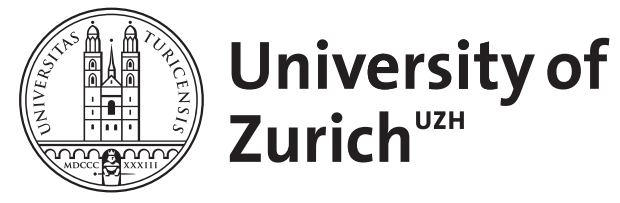

Zurich Open Repository and Archive

University of Zurich

University Library

Strickhofstrasse 39

CH-8057 Zurich

www.zora.uzh.ch

Year: 2019

\title{
Klage und Ehre. Zur Verdrängung der Klage und ihrer Bedeutung für spätmoderne Formen der Ehre
}

Wüthrich, Matthias D

Posted at the Zurich Open Repository and Archive, University of Zurich

ZORA URL: https://doi.org/10.5167/uzh-184719

Journal Article

Accepted Version

Originally published at:

Wüthrich, Matthias D (2019). Klage und Ehre. Zur Verdrängung der Klage und ihrer Bedeutung für spätmoderne Formen der Ehre. Jahrbuch für biblische Theologie, 32(2017):221-249. 


\section{Klage und Ehre}

\section{Zur Verdrängung der Klage und ihrer Bedeutung für spätmoderne Formen der Ehre}

„Mein Gott, mein Gott, warum hast Du mich verlassen?“ (Mk 15,34, par. Mt 27,46) Der markinische und matthäische Jesus betet am Kreuz schreiend einen Klagepsalm. Sofern Jesu Rede $z u$ Gott immer auch ein inhaltliches Reden von Gott impliziert ${ }^{1}$ und systematische Theologie als Interpretation des Wahrheitsanspruches und der Orientierungsleistungen christlicher Rede von Gott zu verstehen ist, stünde zu vermuten, dass nicht nur Jesu Klage ${ }^{2}$, sondern diese Gebetsform als solche für die systematische Theologie von entscheidender Bedeutung wäre. Vor dem Hintergrund der jesuanischen Evokation der Klage ist darum prima vista erstaunlich, dass sich nicht nur die Kirche, sondern auch die theologische Tradition und allen voran die systematische Theologie mit der Klage stets schwer getan hat und noch heute schwer tut. Oswald Bayers Beobachtung ist noch immer treffend: „Seit den ältesten Zeiten der Kirche ist die Klage im Gottesdienst fast erloschen, im alltäglichen Leben der Christen durch den Einfluss der Stoa - zurückgedrängt und, wo sie elementar hervorbricht, ohne Form; die systematisch-theologische Reflexion endlich hat sie fast völlig vernachlässigt. Mit der Aufnahme der Psalmen Israels als Urgebete [...] auch der Kirche verschwand sie faktisch zwar nicht, aber ihrer fundamentalen Bedeutung wurde in der Liturgie und in der Theol[ogie] keineswegs Rechnung getragen. Bis heute bildet sie keinen entscheidenden Gesichtspunkt der Dogmatik und Ethik und findet in die Begriffssystematik der massgebenden Handbücher und Lexika nur langsam Eingang. “3

In den letzten Jahren sind nun einige systematisch-theologische Studien zur Gebetsform der Klage erschienen. ${ }^{4}$ In diesen Studien deutet sich ein wachsendes Interesse an der Bedeutung der Klage für die Systematische Theologie an. Dennoch scheinen dabei die programmatischen, systematisch-theologischen Klage-Beiträge, die bereits 2001 im Jahrbuch

\footnotetext{
1 Klagegebete sind als verdichtete Texte öffentlicher und wahrheitssuchender Glaubenskommunikation in gewissem Sinne selbst als Vollzugsformen systematisch-theologischen Nachdenkens zu begreifen. So im Blick auf die Psalmen auch: G. Thomas, Die Affizierbarkeit Gottes im Gebet. Eine Problemskizze, in: A. Grund/A. Krüger/F. Lippke (Hg.), Ich will Dir danken unter den Völkern. Studien zur israelitischen Gebetsliteratur (FS B. Janowski), Gütersloh 2013, 709-731, 709f.

${ }^{2}$ Die systematisch-theologische Bedeutung der Klage Jesu hat zum Beispiel Jürgen Moltmann zur Geltung gebracht: J. Moltmann, Der gekreuzigte Gott. Das Kreuz Christi als Grund und Kritik christlicher Theologie, München 1972, 138-146.

${ }^{3}$ O. Bayer, Art. Klage, $\mathrm{RGG}^{4}$ IV (2001), 1391f, 1391. Vgl. ebenfalls mit Blick auf die systematische Theologie die ähnlich gelagerte Kritik bei B. Janowski, Konfliktgespräche mit Gott. Eine Anthropologie der Psalmen, Neukirchen-Vluyn 2003, 36.

4 Für den Bereich der deutschsprachigen systematische Theologie vgl. die folgenden Monographien oder Sammelbände: M. L. Frettlöh, Gott, wo bist Du? Kirchlich-theologische Alltagskost, Bd. 2 (Erev-Rav-Hefte 11), Wittingen 2009; E. Harasta (Hg.), Mit Gott klagen. Eine theologische Diskussion, Neukirchen-Vluyn 2008; C. Welz, Vertrauen und Versuchung (Religion in Philosophy and Theology 51), Tübingen 2010, v.a. 13-32; M. D. Wüthrich, Gott und das Nichtige. Eine Untersuchung zur Rede vom Nichtigen ausgehend von $\$ 50$ der Kirchlichen Dogmatik Karl Barths, Zürich 2006, 337-377. - Die monographische Untersuchung von Jochen Schmidt widmet sich der Klage grösstenteils als allgemeinem Daseinsvollzug in anthropologischer und produktions- und rezeptionsästhetischer Perspektive und in diesem Kontext dann (erst gegen Ende) der Klage als Gebet. V.a. J. Schmidt, Klage. Überlegungen zur Linderung reflexiven Leidens (Religion in Philosophy and Theology 58), 154-176. - Zur englischsprachigen Literatur vgl. K.D. Billman/D.L. Migliore, Rachel's Cry. Prayer of Lament and the Rebirth of Hope, Cleveland 1999; R.A. Hughes, Lament, Death, and Destiny, New York u.a. 2004; E. Harasta/B. Brock, Evoking Lament. A Theological Discussion, London/New York 2009 (= Übersetzung von „Mit Gott klagen”, s.o.); D. Ngien, Fruit for the Soul: Luther on the Lament Psalms, Minneapolis 2015. - Aus der sehr überschaubaren Menge von systematisch-theologischen Artikeln in Zeitschriften seien exemplarisch genannt: L. Bendel-Maidl, Die Klage als Weg, das Böse mit Gott ins Gespräch zu bringen, Münchener theologische Zeitschrift, 52 (2001), 234-244; N. Wolterstorff, If God is good and sovereign, why lament?, Calvin Theological Journal, 36 (2001), 42-52.
} 
für Biblische Theologie (JBTh 16) veröffentlicht wurden, noch immer unerreicht, was ihre Versuche angeht, das Innovationspotential der Gebetform der Klage für systematischtheologische Denkstrukturen herauszustellen. ${ }^{5}$ So dass man nun auf das Ganze besehen doch feststellen muss, dass die systematische Theologie noch immer weit davon entfernt zu sein scheint, das spezifische Reden der Klage zu Gott und von Gott, ihre Inhalte, ihre Denk- und Vollzugsformen hinreichend reflektiert zu haben und in den eigenen Denkstrukturen zur Geltung bringen zu können. ${ }^{6}$

Mit dem folgenden Beitrag geht es uns aber nicht um einen klagesensiblen Umbau dogmatischer Denkstrukturen. Wir bewegen uns damit vielmehr im Vorfeld dieses Desiderates, indem wir zunächst darüber nachdenken möchten, wie es in der systematischen Theologie zu den Blockaden kommt, die verhindern, dass die Klage in ihr angemessen zur Geltung gebracht werden kann (1. Kapitel). Aus der Analyse dieser Blockaden ergibt sich dann auch die Beobachtung einer defizitären phänomenalen Wahrnehmung der Klage und ihres Aktualitätsbezuges. Entsprechend widmen sich das 2. und 3. Kapitel des Beitrages exemplarisch der Analyse eines Phänomens, an dem dieser Aktualitätsbezug aufgezeigt werden kann, nämlich der menschlichen „Ehre“. Der Beitrag verfolgt also ein doppeltes Ziel: Er möchte der Klage zu einer angemesseneren Wahrnehmung und Geltung in der systematischen Theologie verhelfen, indem er wichtige doktrinale Scharnierstellen benennt, die dieses Anliegen verhindern, und indem er gleichzeitig die lebenspraktische Bedeutung der Klage im Blick auf das systematisch-theologisch bzw. ethisch relevante Phänomen der Ehre herausarbeitet.

\section{Gründe für die Verdrängung der Klage in der systematischen Theologie}

Wir gehen von der Annahme aus, dass die fehlende Reflexion und Bedeutung der Klage ${ }^{7}$ in der systematischen Theologie nicht einfach ein Zufallsprodukt der Theologiegeschichte, sondern das Resultat spezifischer Glaubensrationalitäten darstellt. Wir möchten darum von einer Verdrängung der Klage in der systematischen Theologie zu reden. Mit der Begriff der Verdrängung sei angezeigt, dass es sich sowohl um ein unintendiertes Aufmerksamkeitsdefizit handeln kann als auch um einen reflektierten, normativen Geltungsentzug $^{8}$. Uns interessiert v.a. letzteres. Es geht also im Folgenden um den Versuch, die wichtigsten doktrinalen Gründe jener Verdrängung zu rekonstruieren. ${ }^{9}$

\subsection{Entrechtung der Theodizeefrage}

\footnotetext{
${ }^{5}$ Ich denke dabei an die Beiträge von O. Bayer, Zur Theologie der Klage, JBTh 16 (2001), 289-301; O. Fuchs, Unerhörte Klage über den Tod hinaus! Überlegungen zur Eschatologie der Klage, JBTh 16 (2001), 347-379; J. Reikerstorfer, Über die „Klage“ in der Christologie, JBTh 16 (2001), 269-287; Ottmar Fuchs, dessen Forschungen sich seit seiner Habilitationsschrift (Die Klage als Gebet. Eine theologische Besinnung am Beispiel des Psalms 22, München 1982) immer wieder kreativ mit der Theologie der Klage befassen, hat auch in den letzten Jahren die Thematik intensiv weiterverfolgt: Vgl. etwa seine Ausführungen zur Klage in: Da Jüngste Gericht. Hoffnung auf Gerechtigkeit, Regensburg ${ }^{2} 2009$, bes. 77ff; oder in: Der zerrissene Gott. Das trinitarische Gottesbild in den Brüchen der Welt, Ostfildern ${ }^{2} 2014$.

${ }^{6}$ Zur Notwendigkeit dieses zur Geltungbringens vgl. auch: Thomas, Affizierbarkeit, 709f.

${ }^{7}$ Unter Klage sei hier die ausgesprochene oder schweigende Rede zu Gott im Sinne eines Protestes, Schreiens, Fluchens, Flehens, Seufzens vor, mit und gegen Gott verstanden. (Zu fragen bleibt gerade bei einer so stark körperexpressiven Gebetsform, inwieweit nicht auch nonverbale, hermeneutisch im Horizont des Gebets lokalisierbare Gesten noch als Klagen angesprochen werden können.) Als Klage werden hier sowohl freie als auch schriftlich fixierte, neuere als auch alte, traditionelle Gebetsformen verstanden. Auch einzelne Klageelemente oder Erwähnungen der Klage innerhalb etwa von Dankesliedern (vgl. Ps 30,12) können gemeint sein. Trotz dieses weiten Begriffes steht in den folgenden Ausführungen in erster Linie die alttestamentliche Vielfalt geprägter Klagegebete und da insbesondere das Klagelied des Einzelnen vor Augen. Als klassisches Beispiel dafür gilt in der alttestamentlichen Exegese meist Ps 13 (vgl. Janowski, Konfliktgespräche, 57).

${ }^{8}$ Wobei der Geltungsentzug natürlich auch auf die Aufmerksamkeit zurückwirkt.

${ }^{9} \mathrm{Ob}$ und wie diese Gründe aufeinander bezogen sind, muss offen gelassen werden.
} 
Wir beginnen mit dem wichtigsten Punkt und formulieren thetisch: Der Grund der spezifischen Verdrängung des Klagegebetes als Reflexionsgegenstand der systematischen Theologie liegt in der dogmatischen Entrechtung der Theodizeefrage. Diese Entrechtung geschieht wiederum durch verschiedene Formen der Theodizee oder theodizeeanaloger Denkstrukturen.

Bevor diese These genauer entfaltet wird, sind zwei Vorbemerkungen anzubringen:

1. Auf der Ebene der Glaubenspraxis und des Gebetsvollzuges bildet die Theodizeefrage ein zentrales Ausdruckselement der Klage. Man denke an Fragen wie: „Du aber, Herr, wie lange?“ (Ps 6,4) oder: „Wie lange, Herr, willst Du meiner so ganz vergessen?“ (Ps 13,2) oder: „Mein Gott, mein Gott, warum hast Du mich verlassen?“ (Ps 22,2). Unsere These geht davon aus, dass diese enge Verflochtenheit von Theodizeefrage und Klage auch auf der reflexiven systematisch-theologischen Ebene spielt und die Urteilsbildung hinsichtlich der Klage prägt, selbst wenn die Theodizeefrage auf dieser Ebene später eine abstraktere Form annimmt, nämlich die Form der radikalen und umfassenden Frage nach Gottes Allmacht und Güte oder Gottes Gerechtigkeit (wobei die Frage faktisch auch weitere Eigenschaften Gottes involviert) angesichts des Bösen (in einem weiten Sinne) in der Welt.

2. Die systematisch-theologische Entrechtung der Theodizeefrage erfolgt gemäss der obigen These nicht nur durch verschiedene Formen der Theodizee - also durch den expliziten Versuch einer theoretischen Rechtfertigung Gottes angesichts des Bösen. ${ }^{10}$ Die Entrechtung erfolgt auch durch theodizeeanaloge Denkstrukturen. Der Begriff der Theodizeeanalogie ist kurz zu erläutern: Der Begriff „Theodizee“" ist ein neuzeitlicher, er wurde bekanntlich durch Gottfried Wilhelm Leibniz in seinen „Essais de Théodicée“"11 (1710) geprägt. Sofern mit dem Begriff der Theodizee eine spezifisch neuzeitliche, kritische Verschärfung der Gottesfrage verbunden ist ${ }^{12}$, ist es nicht ratsam, ihn direkt auf affine Denkstrukturen in der Antike und im Mittelalter anzuwenden. Andererseits zeigt schon ein Blick auf Hiob, dass das Sachproblem viel älter ist als der Begriff „Theodizee“. Entsprechend schlagen auch wir hier vor, im Blick auf vorneuzeitliche Denkstrukturen, die dieses Sachproblem betreffen, von Theodizeeanalogien ${ }^{13}$ bzw. von theodizeeanalogen Denkstrukturen sprechen. Damit seien hier alle historischen Versuche einer theologischen oder philosophischen Rechtfertigung oder zumindest einer impliziten Entlastung Gottes angesichts des Bösen (im weiten Sinn) bezeichnet. ${ }^{14}$

Theodizeeanaloge Denkstrukturen können in der Entwicklung der Theologie an verschiedenen Stellen ausgemacht werden. Meist wird diesbezüglich Augustin eine prägende Rolle zugesprochen. So spricht John Hick etwa in seinem Buch „Evil and the God of Love“ von einem abendländisch dominanten augustinischen Theodizeetypus, den er von einem weit weniger einflussreichen irenäischen Theodizeetypus unterscheidet. ${ }^{15}$

\footnotetext{
10 Wir sehen hier ab von weiteren Differenzierungen wie sie in der analytischen Religionsphilosophie vorgenommen werden, etwa der Unterscheidung zwischen theodicy und defense (klassisch bei A. Plantinga, God, Freedom and Evil, London 1975, 63; ders., Epistemic Probability and Evil, in: M.M. Olivetti (Hg.), Teodicea oggi? (Archivio di Filosophia 56), Padua 1988, 557-584, 561; oder zusammenfassend: ders., SelfProfile, in: J.E.Tomberlin/P. Van Inwagen (Eds), Alvin Plantinga, Dordrecht/Boston/Lancatser 1985, 3-97, 42) oder der Differenzierung zwischen einer Theodizee im Sinne der direkten Rechtfertigung Gottes und im Sinne einer rationalen Rechtfertigung des theistischen Bekenntnisses (also nicht Gottes, sondern des Glaubens an Gott) (so z.B.: A. Kreiner, Gott im Leid. Zur Stichhaltigkeit der Theodizee-Argumente, Freiburg i.Br. 2005, $24 \mathrm{f}$; $C$. Link, Theodizee [Theologische Bibliothek III], Göttingen 2016, 17).

${ }^{11}$ Vgl. G.W. Leibniz, Essais de théodicée sur la bonté de Dieu, la liberté de l' homme et l' origine du mal/Die Theodizee von der Güte Gottes, der Freiheit des Menschen und dem Ursprung des Übels, zweisprachige Ausg. hg. u. übers. v. H. Herring, in: Gottfried Wilhelm Leibniz, Philosophische Schriften Bde II/1 u. II/2, Darmstadt 1985.

${ }^{12}$ Vgl. z.B. Link, Theodizee, 16-19.

13 Vgl. zum Begriff der Theodizeeanalogie: C.-F. Geyer, Art. Theodizee, Philosophisch, in: TRE XXIII, Berlin/New York (2002), 231-237, 232.

14 Ähnlich: H. Kessler, Gott und das Leid seiner Schöpfung. Nachdenkliches zur Theodizeefrage, Würzburg 2000, 13f.

${ }^{15}$ J. Hick, Evil and the God of Love, rev. Ed. San Francisco ${ }^{2} 1977$, zum augustinischen Typus: 38-198, zum irenäischen Typus: 201-240. - Hans Kessler unterscheidet im Blick auf Augustin selbst eine ordnungstheoretische, privationstheoretische und (erb-)sündentheoretische Theodizeeanalogie. Kessler, Gott, 2237.
} 
Als Grundzüge des augustinischen Theodizeetypus nennt Hick: 1. die Betonung der Güte des geschaffenen Universums; 2. die Vorstellung, dass das Böse menschlich freiem Willen entstammt, als Sünde ausgelegt wird ${ }^{16}$ und von da her menschliches Leiden als Strafe für Sünde (sowohl Tat- wie Erbsünde) zu deuten ist; 3. die freilich durch den Gedanken ewiger Höllenstrafen durchkreuzte Vorstellung einer Zulassung der Sünde durch Gott um des höheren Gutes der Erlösung willen (felix culpa); 4. die v.a. im Privationsgedanken (malum est privatio boni) zum Ausdruck gebrachte ontologische Depotenzierung des Bösen; 5. die Vorstellung eines metaphysischen Übels oder zumindest einer metaphysischen Unvollkommenheit und Schwäche des Geschaffenen - die dann wiederum auf die Möglichkeit der Sünde bezogen wird; 6. den Versuch, das Böse durch ästhetische Betrachtung funktional in den Kosmos einzuordnen.

Es fragt sich, ob Hick nicht doch allzu Heterogenes spannungsvoll in den augustinischen Typus presst. ${ }^{17}$ Zudem wäre zu fragen, ob er der traditionellen Satanologie nicht zu wenig Aufmerksamkeit geschenkt hat. ${ }^{18}$ Doch an seiner Systematisierung wird immerhin ersichtlich, wie stark die abendländische Theologie von theodizeeanalogen Denkstrukturen geprägt ist. Diese Einschätzung teilen auch Walter Gross/Karl-Josef Kuschel, wenn sie summarisch festhalten: „Seit Augustin war der Versuch, das Verhältnis von Gott und dem Übel zu klären, stets ein Versuch der Entlastung Gottes und der Belastung des Menschen gewesen. [...] Man meinte, Gott von jeder Verantwortung freisprechen zu müssen[] und griff zu Privations-, Zulassungs-, Straf-, und Erziehungstheorien, um jede Frage nach der Verantwortung von Gott ab- und auf den Menschen umzubiegen." ${ }^{19}$ So vielfältig auch die Theologien waren, in denen theodizeeanaloge Denkstrukturen aufgebaut, tradiert und reproduziert wurden, so lässt sich doch als grobe Matrix ihrer Theodizeen bzw. Theodizeeanalogien die variable Denkfigur einer Entlastung Gottes via Belastung des Menschen und Entbösung des Bösen beobachten. Dabei ist in Rechnung zu stellen, dass sich die Entlastungsfunktion jeweils an der immanenten und zeitbedingten Logik einer theologischen Konzeption bemisst. So stand etwa der Prädestinationsgedanke bei Augustin damals - entgegen einer heutigen Sichtweise - nicht quer zu seinen anderen Entlastungsversuchen. ${ }^{20}$

Das Dilemma des „augustinischen Theodizeetypus“ liegt auf der Hand: „Die klassischen Theorien können nicht beides erreichen, was sie erreichen wollen: die Erfahrungen der Menschen ernst nehmen und zugleich Gott entlasten. ${ }^{\text {“21 }}$ Und so bildete sich denn im 20. Jahrhundert in einigen Theologien u.a. unter dem Einfluss der grauenhaften Erfahrungen von „Auschwitz“ eine weitere theodizeeanaloge Entlastungsstruktur aus: nämlich die „These vom leidenden Gott“". ${ }^{22}$ Sie knüpft dabei an unaufgebbare Einsichten neuerer Theologie in ihrer Abwendung vom Apathie-Axiom an. Die These vom leidenden Gott radikalisiert diese Abwendung aber so konsequent, dass Gott in seiner Selbstbeschränkung gegenüber der Welt,

\footnotetext{
${ }^{16}$ Diesen Gedanken betont John Hick weniger in den Grundzügen des augustinischen Theodizeetypus als bei seiner Abhandlung über Augustin selber. Hick, Evil, 59-69, bes. 59.62.

17 So gehören zum augustinischen Theodizeetypus bei Hick nicht nur Augustin, sondern auch Thomas von Aquin und die katholische Augustinrezeption bis zur Gegenwart, Johannes Calvin, Gottfried Wilhelm Leibniz und Karl Barth.

${ }^{18}$ Hick deutet die theodizeeanaloge Funktion der Vorstellung des Teufels nur am Rande an (z.B. ebd., 62); zur Unterbestimmung des Teufelsproblems ebd., 13.

${ }^{19}$ W. Gross/K.-J. Kuschel, „Ich schaffe Finsternis und Unheil!“ Ist Gott verantwortlich für das Übel?, Mainz ${ }^{2}$ 1995, 197. Vgl. H. Blumenberg, Die Legitimität der Neuzeit, erneuerte Ausg., Frankfurt a.M. 1996, $145-147$. Vgl. auch J.B. Metz, Theologie als Theodizee?, in: W. Oelmüller (Hg.), Theodizee - Gott vor Gericht?, München 1990, 103-118, 107ff.

${ }^{20}$ Vgl. dazu Blumenberg, Legitimität, 148; Hick, Evil, 63-69, bes. 63.66 - wobei bei Augustins Schrifttum immer auch die historische Entwicklung der Theologumena mitbedacht werden muss.

${ }^{21}$ W. Dietrich/C. Link, Die dunklen Seiten Gottes. Bd. 2: Allmacht und Ohnmacht, Neukirchen-Vluyn 2000, 297.

${ }^{22}$ Dietrich/Link, Die dunklen Seiten, Bd.2, 296; zur kritischen Diskussion der These ebd., 296ff. Zur Kritik vgl. in ähnlicher Weise Gross/K.-J. Kuschel, „Ich schaffe Finsternis“, 202-205.207f.210f. Vgl. auch: Link, Theodizee, 210-220.
} 
in seinem leidenden Verhältnis zu ihr gleichsam aufgeht ${ }^{23}$ - ja zuweilen untergeht (vgl. die Rede von einem spezifischen „Tod Gottes“). So verschieden diese These auch entfaltet werden mag, ihre theodizeeanaloge Struktur ist deutlich: „Wer Gott von der Urheberschaft der weltgeschichtlichen Katastrophen freisprechen will, muss ihn dem Leiden unterwerfen, ihn gewissermassen ,verohnmächtigen“ - und zwar von Anfang an. ${ }^{\text {“24 }}$ Der Preis eines solchen oder ähnlich gelagerten Entlastungsversuches Gottes ist freilich nicht gering: Man kann sich etwa fragen, ob es im Zuge dieser These nicht zu einer unterschwelligen Verdoppelung menschlichen Leidens, gar zu einer Verewigung des Leidens kommt. ${ }^{25}$ Weiter kann man fragen, ob die Entlastungsversuche nicht dazu führen, dass das Böse (in einem weiten Sinne) ,als eine theologische Herausforderung, als Anfrage an Gottes Schöpfung, zum Verschwinden gebracht wird und sich nur noch als ein anthropologisches Problem, als Problem des Menschen melden kann. Es wird moralisiert und damit verharmlost. ${ }^{\text {“26 }}$ In dieser Hinsicht weist die These vom leidenden Gott eine heimliche Affinität zu den Entlastungsversuchen des augustinischen Theodizeetypus auf. Von der biblischen Rede von der Kraft und (Heils-)Macht Gottes her (z.B. in alttestamentlichem Bezug: Lk 1,46-55) wird man die Rede vom Leiden Gottes kaum so einseitig lösen dürfen, wie das in der genannten These der Fall ist.

Wir haben in einem typologisierenden Verfahren zwei markante Beispiele von theodizeeanalogen Denkstrukturen skizziert: die Denkstrukturen, die sich im Wirkfeld des „augustinischen Theodizeetypus“ ausgebildet haben und diejenigen, die sich im Kontext der These vom leidenden Gott ausgebildet haben. Damit sei nicht suggeriert, die Theologiegeschichte habe nur zwei Theodizeetypen mit entsprechenden theodizeeanalogen Denkstrukturen hervorgebracht ${ }^{27}$. Wie erwähnt hat Hick neben dem ,augustinischen Theodizeetypus“ auch noch einen ,irenäischen Theodizeetypus“ identifiziert ${ }^{28}$. Eine weitere, von allen dreien klar unterschiedene theodizeeanaloge Denkstruktur bildet die Lehre vom Nichtigen bei Karl Barth ${ }^{29}$. Ich habe an anderer Stelle gezeigt, dass - entgegen der Deutung von John Hick ${ }^{30}$ - Barths Lehre vom Nichtigen keinem der traditionellen Theodizeetypen zugeordnet werden kann und er mehr oder weniger sämtliche theodizeeanalogen Denkstrukturen der Tradition transformiert oder verabschiedet. ${ }^{31}$ Trotzdem kann man auch bei Barth so etwas wie eine „christologische Theodizee“ - verstanden als Selbstrechtfertigung Gottes in Jesus Christus - finden. An Barths Lehre vom Nichtigen lässt sich denn auch schön andemonstrieren, wie es in sachlichem Zusammenhang mit dieser „Theodizee“ zu einer Zurückdrängung des theologischen Rechtes der Klage kommt, ${ }^{32}$ so dass sich im Blick auf

\footnotetext{
${ }^{23}$ Vgl. etwa J. Moltmann, Der gekreuzigte Gott; und jüdischerseits: H. Jonas, Der Gottesbegriff nach Auschwitz. Eine jüdische Stimme, Frankfurt a.M. 1987.

${ }^{24}$ So Dietrich/Link, Die dunklen Seiten, Bd.2, 297.

${ }^{25}$ Ebd., 300.

${ }^{26}$ Ebd., 301.

${ }^{27}$ Die beiden theodizeeanalogen Denkstrukturen entsprechen ungefähr der typologisierenden Unterscheidung von «christlichen Theismus» und «christlichen A-Theismus», die Ulrich Hedinger beide der Versöhnung Gottes mit dem Elend bezichtigt: U. Hedinger, Wider die Versöhnung Gottes mit dem Elend. Eine Kritik des christlichen Theismus und A-Theismus (BSHST 60), Zürich 1972, 33-101, zusammenfassend 74f.

28 John Hick rechnet dazu die theodizeeanalogen Denkstrukturen von Irenäus und anderen östlichen Kirchenvätern sowie - in Ansätzen - die späteren orthodoxen Theologien, v.a. aber die Denkstrukturen von Friedrich Schleiermacher (Hick, Evil, 201-235, vgl. 236-240).

${ }^{29}$ Die Lehre vom Nichtigen wir komprimiert entfaltet in $§ 50$, Bd. III/3, in: K. Barth, Die Kirchliche Dogmatik, Bde I/1-IV/4, Zürich 1932-1967 (abgekürzt im Folgenden: KD).

${ }^{30}$ Zu Barth: Hick, Evil, 126-144.

${ }^{31}$ Wüthrich, Gott, 67-70.215-263.364-368.

${ }^{32}$ In Barths Lehre vom Nichtigen selbst: KD III/3, 336. Deutlich wird das v.a. in Barths Hiobauslegung: KD IV/3, 443-448; 459-470; 486-499; 522-531. Es lassen sich in KD und auch in früheren Schriften Barths zwar durchaus Passagen finden, wo er der Klage ein grösseres Recht einräumt als in der Hiobsauslegung. Klagekritische Aussagen dominieren jedoch in KD. - Vgl. zur theodizeemotivierten Verdrängung der Klage
} 
Barth exemplarisch unsere eingangs aufgestellte These bestätigt: Wo die Theodizeefrage durch eine „Theodizee“ oder theodizeeanaloge Denkstrukturen theologisch entrechtet wird, da wird auch das theologische Recht der Klage untergraben. ${ }^{33}$

Um Missverständnisse zu vermeiden sei abschliessend betont, dass unsere Analysen zur theodizeemotivierten Verdrängung der Klage gerade nicht auf eine Schwächung der Christologie abzielen. Denn der Gekreuzigte legt die Klage nicht still, sondern evoziert sie „laut" (Mt 15,34.37). Die Einsicht in die Art wie Gott in Jesus Christus dem Nichtigen in seiner Inkarnation, als „Heiland“, am Kreuz und in der Auferstehung entgegentritt, offenbart die ganze, unheimliche Destruktivität dieses Nichtigen (auch gerade in seiner prekären Gestalt als Sünde) und entfacht so allererst die in der Klage evozierte Sehnsucht nach ihm als unserem eschatischen Erlöser. Die Christologie ist nicht Verhinderungs-, sondern gerade Ermöglichungsgrund der Klage.

Bei den folgenden Gründen für die Verdrängung der Klage müssen wir uns kürzer halten und uns auf Andeutungen beschränken.

\subsection{Gebets-theologische Gründe}

Die Ursachen der Verdrängung der Klage in der systematischen Theologie sind nicht nur in ihren Theodizeen und theodizeeanalogen Denkstrukturen, sondern auch in der Theologie des Gebets zu suchen. Zwei Punkte scheinen dabei vorrangig:

1. Als Gebetsform hat die Klage Teil an der neuzeitlichen Krise des Gebets ${ }^{34}$, die wiederum mit der Krise des Gottesgedankens verbunden ist ${ }^{35}$. Vor dem Hintergrund dieser Krise ist die Verdrängung der Klage auch als Ausdruck einer grundlegenden Schwierigkeit der systematischen Theologie zu verstehen, die naiv realistischen, imaginativen, poetischen und bildhaften Züge der biblischen Gottesrede und besonders die darin zum Ausdruck gebrachten „dunklen Seiten“ Gottes als ein angemessenes, gültiges Reden von Gott zu interpretieren und dabei die spannungsvolle Einheit des Gottesbildes so zu wahren, dass weder seiner moralischen Banalisierung oder „Halbierung“ einerseits noch seiner Dämonisierung andererseits das Wort geredet wird. $^{36}$ Günter Thomas hat zudem auf eine weitere gebetstheologische Schwierigkeit der Gottesrede hingewiesen: Sie liegt darin, dass sich die systematische Theologie bis in die Gegenwart hinein damit schwer tut, ein effektives Affiziertwerden Gottes jenseits einer abstrakten Allwirksamkeit und Allwissenheit zu denken,

insgesamt und besonders zu Barths christologischer Theodizee und ihrer Verdrängung des theologisches Rechtes der Klage: Wüthrich, Gott, 359-375.

33 Ottmar Fuchs hat bereits in seiner Habilitationsschrift auf den Zusammenhang von Theodizee und Verdrängung der Klage hingewiesen (Fuchs, Die Klage, 341-345.354-359). Seine später auf dieser Linie erhobene Forderung einer „Entrechtfertigung Gottes“ bzw. einer Art „negativer Theodizee“ scheint mir durchaus berechtigt (Fuchs, Der zerrissene Gott, 22), auch wenn ich der in diesem Buch vorgelegten trinitätstheologischen Entfaltung dieser Forderung nicht an allen Punkten zustimmen kann.

${ }^{34}$ Vgl. exemplarisch die Gebetskritik Kants, der das Gebet als ,abergläubische(n) Wahn“ bezeichnet hat. I. Kant, Die Religion innerhalb der Grenzen der blossen Vernunft, in: ders., Werke in sechs Bänden, hg. v. W. Weischedel, Bd. IV, 645-879, 870. Für eine Analyse zu Kants Kritik vgl. C.J. Janowski, Beten ohne bitten? Zum Problem der Aufzehrung des Gebets und des Betens in I. Kants Religionsphilosophie, in: Grund/Krüger/Lippke (Hg.), Ich will Dir danken, 671-708, bes. 678-695. Zur neuzeitlichen Gebetskritik insgesamt vgl. die Analysen bei H.-J. Luibl, Des Fremden Sprachgestalt. Beobachtungen zum Bedeutungswandel des Gebets in der Geschichte der Neuzeit, Tübingen 1993.

${ }^{35}$ Z.B. R. Schäfer, Gott und Gebet. Die gemeinsame Krise zweier Lehrstücke, ZThK 65 (1968), 117-128.

${ }^{36}$ Vgl. B. Janowski, Ein Gott, der straft und tötet? Zwölf Fragen zum Gottesbild des Alten Testaments, Neukirchen-Vluyn 2013, 170f.173f (in Anschluss u.a. an Jan-Heiner Tück). Vgl. auch Thomas, Affizierbarkeit, 709f. Bereits in seiner Habilitationsschrift hat Ottmar Fuchs die Vermutung geäussert, dass das Verschwinden der Klage mit einer spezifischen Entwicklung der Gotteslehre zusammenhängt. O. Fuchs, Die Klage, 355f. 
ohne damit gleich einer naiven Metaphysik oder einem ebenso naiven Personalismus zu verfallen. ${ }^{37}$

Die genannten Schwierigkeiten betreffen natürlich alle Gebetsformen (und sie wurden v.a. im Blick auf die neuzeitliche Kritik am Bittgebet aufgearbeitet ${ }^{38}$ ). Es steht jedoch zu vermuten, dass sie gerade bei der theologischen Interpretation der Klage mit besonderer Schärfe durchschlagen. Kommt hinzu, dass die vielfach anzutreffende neuzeitliche Tendenz, das Gebet harmonistisch als Prozess der menschlichen Einstimmung in den Willen Gottes zu deuten oder es psychologistisch als Ort geistiger Selbstläuterung zu verstehen, der Klage als einem „Konfliktgespräch mit Gott‘ ${ }^{639}$ (nicht nur vor Gott!) kaum förderlich sein konnte.

2. Es ist unbestritten: Die Gebetsform der Bitte ist die wichtigste Gebetsgattung und zentral für das Gebetsverständnis überhaupt. ${ }^{40}$ Ebenso evident ist, dass im praktischen Gebetsvollzug eine Bitte auch Klagecharakter annehmen kann $^{41}$ und das Klagegebet als ganzes Bittelemente enthält ${ }^{42}$. Doch all das impliziert noch nicht die gebetstheologische Subsumption (im Sinne der asymmetrischen Zuordnung, der Unterordnung oder der Auflösung) der Klage unter die Bitte, wie sie im systematisch-theologischen Kontext dominant anzutreffen ist ${ }^{43}$ - wenn denn die Klage überhaupt in den Blick kommt. Die Verdrängung der Klage hat auch mit dieser Subsumption zu tun.

Um das Gesagte zu illustrieren, sei erneut Karl Barth herangezogen ${ }^{44}$. Denn er entfaltet seine Gebetstheologie primär als Bittgebetstheologie. ${ }^{45}$ Das Gebet ist ,entscheidend, es ist in seiner Mitte, es ist in dem, was es zum Gebet macht Bitte, und nur als Bitte dann auch Dank, Buße und Anbetung." 46 Die Gebetsgattungen „Lob“ und „Klage“ werden hier gar nicht erst erwähnt. Inhaltlich ist die gebetstheologische Verdrängung der Klage wiederum in der Christologie begründet. Wo selbst unser Bitten schon in Christus erhört ist, da ist erst recht unser Klagen bereits überholt. Das wird deutlich in den folgenden Aussagen: „Es gibt eine große Erhörung aller wirklichen, der legitimen und notwendig an Gott gerichteten Bitten. Diese eine große göttliche Gabe und Erhörung ist Jesus Christus. “ Und etwas weiter unten folgt dann: „So ist er (sc. Jesus Christus) die eine große Gabe und Erhörung, in der Alles, was

\footnotetext{
${ }^{37}$ Ebd., bes. 711-714.723-728.

${ }^{38}$ Die theologische Aufarbeitung dieser Kritik ist gerade da weiterführend, wo sie nicht - wie etwa bei $W$. Härle, Den Mantel ausbreiten. Theologische Überlegungen zum Gebet, NZSTh 33 (1991), 231-247 - durch die theodizeeanaloge Wahrung abstrakt bestimmter Gottesprädikate (Allmacht, Allwissenheit, Güte Gottes) gesteuert wird, sondern durch christologische Zugänge wie etwa bei C. Tietz, Was heißt: Gott erhört Gebet?, ZThK 106 (2009), 327-344, oder pneumatologische Zugänge wie etwa bei $R$. Bernhardt, „Nackt vor Gott“. Systematisch-theologische Überlegungen zum Sinn des Bittgebets, in: „Im Namen Gottes...“. Theologie und Praxis des Gebets in Christentum und Islam, Regensburg 2006, 103-118, oder M. Höfner, Krankheit und Gebet. Überlegungen zu Calvin und Schleiermacher, in: G. Thomas/I. Karle (Hg.), Krankheitsdeutung in der postsäkularen Gesellschaft. Theologische Ansätze im interdisziplinären Gespräch, Stuttgart 2009, 465-488.

${ }^{39} \mathrm{Vgl}$. den im Plural und ohne Kursivierung gesetzten Buchtitel Bernd Janowskis: „Konfliktgespräche mit Gott". Im Buch wird jedoch nicht nur die Klage verhandelt.

${ }^{40}$ Zur Zentralität für das Gebetsverständnis: C.J. Janowski, Beten, $674 \mathrm{f}$.

41 So kann etwa die Bitte: „sondern erlöse uns von dem Bösen“ im Gebetsvollzug subjektiv durchaus die emotionale Färbung einer Klage annehmen.

${ }^{42}$ Schon das Klagelied des Einzelnen enthält ja in der Regel ein Element der Bitte, vgl. z.B. Ps 13, $4 \mathrm{f}$.

${ }^{43}$ Für diese Dominanz sei exemplarisch genannt: H.-M. Barth, Wohin-woher mein Ruf? Zur Theologie des Bittgebets, München 1981, der der Klage kaum Aufmerksamkeit schenkt (vgl. höchstens a.a.O., 162.170f) und sie dort, wo sie implizit vorkommt, wie ein Bittgebet versteht.

${ }^{44}$ Gebetstheologische Gründe für die Verdrängung der Klage könnten natürlich in anderer Weise auch bei vielen anderen Theologen wie etwa Johannes Calvin oder Friedrich Schleiermacher namhaft gemacht werden.

${ }^{45}$ Vgl. KD III/4, 106-112, vgl. auch W. Krötke, Der Eifer um Gottes Ehre. Die Bedeutung des Gebets für die Gotteslehre Karl Barths, in: ders., Barmen - Barth - Bonhoeffer. Beiträge zu einer zeitgemäßen christozentrischen Theologie (Unio und Confessio 26), Bielefeld 2009, 291-312, $303 \mathrm{f}$.

${ }^{46} \mathrm{KD}$ III/4, 110, vgl. 106-112, vgl. auch KD III/3, $301 \mathrm{ff}$.
} 
wir empfangen und erbitten können, nicht nur beschlossen, sondern uns schon gegeben, schon für uns gegenwärtig und vorhanden ist. “47

Wo die eben illustrierte Tendenz zur Subsumption der Klage unter die Bitte nicht zu einem Ausfall der Klage führt, ist doch oft mit gewissen Verengungen im Verständnis der Klage verbunden. Das zeigt sich selbst bei einem so wichtigen Verfechter einer Klagetheologie wie Oswald Bayer, der die Klage letztlich allein in ihrer ,erhöhungsgewissen Zuspitzung als Bitte" in den Blick nimmt. ${ }^{48}$ Mit dieser Zuspitzung fallen aber alle Klagegebete unter den Tisch, die intentional unerhört klagen, die die Erhörung nicht mehr antizipatorisch mittransportieren, all diejenigen Klagen, die nicht nur „vor Gott“ klagen, sondern ohne Gott oder gegen Gott, alle ,gottlosen“ Klagen, alle wütenden Proteste und alle archaischen Schreie gegen den Himmel, alle schmerzerfüllten körperlichen Gesten von Menschen, deren Artikulationsvermögen nicht mehr die Stufe expliziter Bitten erreicht (deren Gesten aber biographisch-hermeneutisch immer noch im Raum des Gebets zu lokalisieren sind). ${ }^{49}$

Wir schliessen diesen Abschnitt mit der Einsicht von Ottmar Fuchs: „Auch die intensivste Bitte ersetzt nicht die Klage, sondern steht selbst in der Gefahr, das Beziehungsproblem zwischen Mensch und Gott zu verdrängen und an der Stelle des Kampfes um Vertrauen den Kampf um das Erbetene zu setzen. Die Klage muss von der Bitte unterschieden werden, wenngleich sie auch nicht ohne Letztere auskommt. “60

\subsection{Glaubenspsychologische und weisheitstheoretische Sublimierungen}

Den oben erwähnten Theodizeen und theodizeeanalogen Denkstrukturen (v.a. dem augustinischen Theodizeetypus) stehen verschiedene kognitive Verarbeitungspraktiken von widerständigen Erfahrungen des Bösen und des Leidens nahe. Ihre theoretische Reichweite ist jedoch beschränkter und sie zielen in erster Linie auf glaubenspsychologische Sinnstiftung und spirituelle Entwicklung. Zu diesen Praktiken gehören Deutungen jener Erfahrungen als selbstverschuldet, als Strafe und pädagogisches Besserungsmittel, als endzeitlich vergoltene Prüfung, als göttliches Mittel zur Willensergebung, als demütige Selbstaufopferung und Christusverähnlichung. ${ }^{51} \mathrm{Ob}$ diese Deutungen in sich kohärent verbunden und theologisch reflektiert sind oder als kleinräumige, vereinzelte, rudimentär ausgebildete Alltagsglaubenstheorien vorkommen, sei dahingestellt. Entscheidend ist, dass sie als Rationalisierungen und Narkotisierungen des existenziellen Leidens fungieren und so Sublimierungsstrategien gleichkommen, die die Legitimität der Klage untergraben.

Eine feinsinnigere Sublimierungsstrategie liegt darin, die Klage durch von Weisheit geleitete Trauerarbeit gleichsam zu überwinden und hinter sich zu lassen. Diese Option hat Paul Ricoeur in seinem Essay „Das Böse“ als höchste Stufe einer emotionalen (jedoch Denken und Handeln integrierenden) Antwort auf das Problem des Bösen bezeichnet. Diese höchste Stufe erreichen nur „einige Weise“, sie geht über die vorangehenden Stadien einer „Spiritualisierung der Klage“ hinaus und führt schliesslich dazu, „Gott ohne Grund zu lieben“ wie das vielleicht Hiob getan habe. ${ }^{52}$ Hier wird das Leiden zwar nicht rationalisiert und

\footnotetext{
${ }^{47}$ Beide Zitate: KD III/3, 307. Vgl. zum Bittgebet bei Karl Barth auch: E. Harasta, Lob und Bitte. Eine systematisch-theologische Untersuchung über das Gebet, Neukirchen-Vluyn 2005, 182-232; D.L. Migliore, Freedom to Pray. Karl Barth's Theology of Prayer, in: D.E. Saliers (Ed.), Prayer. Karl Barth (50 ${ }^{\text {th }}$ Anniversary Edition), Louisville/London 2002, 95-113, bes. 109ff; Thomas, Affizierbarkeit, $721 \mathrm{f}$.

${ }^{48}$ Bayer, Zur Theologie, 291.

${ }^{49}$ Auf das sich im Anschluss daran stellende Problem einer „,natürlichen Klagetheologie“ können wir hier nicht tiefer eingehen, auch wenn da gerade von protestantischer Seite her durchaus Denkbedarf herrscht. Vgl. dazu die Impulse von Fuchs, Unerhörte Klage, 372-379.

${ }^{50}$ O. Fuchs, Klage. Eine vergessene Gebetsform, in: H. Becker/B. Einig/P.-O. Ullrich (Hg.), Im Angesicht des Todes. Ein interdisziplinäres Kompendium, Bd.2, St. Ottilien 1987, 939-1024, 953 vgl. 948.

${ }^{51}$ All diese Motive finden sich auch in der Frömmigkeitsliteratur, vgl. A. Holzem, „Kriminalisierung“ der Klage? Bittgebet und Klageverweigerung in der Frömmigkeitsliteratur des 19. Jahrhunderts, JBTh 16 (2001), 153-181.

${ }^{52}$ P. Ricoeur, Das Böse. Eine Herausforderung für Theologie und Philosophie, Zürich 2006, 59.60, vgl. 52-61.
} 
narkotisiert, sondern weise transformiert. Es fragt sich jedoch, ob es möglich und weise ist, Gott ohne Grund zu lieben - und ob das Hiobbuch wirklich darin seine Pointe hat. ${ }^{53}$ Zudem fragt sich, ob für Ricoeur die Klage auf dem Stufenweg der Trauerarbeit nur darum zu einem „Phänomen des Überganges، ${ }^{* 54}$ wird, weil er sie letztlich engführt und immer noch im „Kreislauf der Vergeltung ${ }^{\text {“55 }}$ gefangen sieht. So bildet die Klage trotz ihrer wichtigen Funktion im Prozess der Trauerarbeit eine letztlich unangemessene Form des Umganges mit dem Problem des Bösen.

\subsection{Defizitäre phänomenale Wahrnehmung}

$\mathrm{Zu}$ den Gründen der Verdrängung der Klage gehört schliesslich auch eine defizitäre phänomenale Wahrnehmung der Klage. Sie zeigt sich da, wo die Klage als Ausdruck eines das Gottvertrauen in Frage stellenden, sündigen Jammerns, Haderns und Murrens, einer selbstverkrümmten Gottesnörgelei aufgefasst wird, wo ihre Praxis als kulturelles Phänomen einer verbreiteten Opfermentalität (,culture of complaint ${ }^{456}$ ) gedeutet wird. Als defizitär bzw. schlichtweg falsch ist diese Wahrnehmung insofern zu bezeichnen, als die alttestamentliche Exegese herausgearbeitet hat, dass die Klage nicht nur in einzelnen Elementen der Vertrauensäusserung, sondern auch als Gebetsform insgesamt eine intensivierte Glaubensbekundung darstellit ${ }^{57}$ - und sich so von ausschliesslich selbstreferenziellen Formen der Selbstbemitleidung hinreichend klar unterscheiden lässt. Vielmehr muss dann gefragt werden, ob nicht das fehlende oder vermiedene „Konfliktgespräch“ mit Gott als mangelndes Vertrauen in die Gottesbeziehung zu deuten wäre - und sich die Sünde gerade in einer verkrampften Klageabstinenz zeigen könnte.

Die nicht nur in der Glaubenspraxis ${ }^{58}$, sondern auch in der theologischen Tradition weithin verbreitete $^{59}$ Abschiebung der Klage in die Hamartiosphäre ist ein Hinweis auf eine theologisch defizitäre und reduktive phänomenale Wahrnehmung der Gebetsform der Klage, ihrer Anthropologie und Theo-logie. Einer solchen Wahrnehmung entspricht dann notwendigerweise auch ein Wahrnehmungsdefizit im Blick auf mögliche Aktualitätsbezüge des Klagegebetes.

Im Folgenden wird versucht, exemplarisch wenigstens einen Aktualitätsbezug herauszuarbeiten und damit ein Plädoyer für eine umfassendere phänomenale Wahrnehmung (und damit auch Geltung) der Klage in der systematischen Theologie ${ }^{60}$ vorzunehmen. Gegenstand des Aktualitätsbezuges ist das nicht nur zeitdiagnostisch und gesellschaftlich, sondern auch systematisch-theologisch bzw. ethisch relevante Thema „Ehre“. Das Ziel der folgenden beiden Kapitel ist es, die lebenspraktische Aktualität der Klage dadurch zu erweisen, dass gezeigt wird, worin ihre Bedeutung für das Thema „Ehre“ liegt. Die mit dem

\footnotetext{
${ }^{53}$ Anders B. Janowski, Ein Gott, 205-231, bes. 228f.

${ }^{54}$ So zu Recht die gleichgelagerte Kritik von Welz, Vertrauen, 29.

${ }^{55}$ Ricoeur, Das Böse, 60.

${ }^{56}$ Billman/Migliore, Rachel's Cry, $16 f$.

${ }^{57}$ Zum Vertrauensmotiv als dem Basismotiv des Klagelieds z.B. Janowski, Konfliktgespräche, 81. Dabei ist hervorzuheben, dass die Betenden nicht nur während des ganzen Betens auf Gott vertrauen, sondern ihr Vertrauen auch eine der Klage vorausgehende, in früheren Heilstaten Gottes fundierte Bedingung dafür ist, dass sie überhaupt zu klagen anheben. Es ist nämlich auffällig, dass das Lob am Schluss von Klagepsalmen häufig im Perfekt formuliert ist und die Klagenden in ihrer Rettungsgewissheit von der zeitlichen Logik her vor die Klage zurückblicken. Vgl. K. Schmid, Was heisst Vertrauen? Biblische Erkundungen anhand von Ps 13 und der Abrahamüberlieferung der Genesis, in: I.U. Dalferth/S. Peng-Keller (Hg.), Gottvertrauen. Die ökumenische Diskussion um die Fiducia, QD 250, Freiburg i.Br. u.a. 2012, 31-47.

${ }^{58}$ Vgl. exemplarisch für die Frömmigkeitsliteratur des 19. Jahrhunderts: Holzem, „Kriminalisierung“.

59 Es gab immer auch Ausnahmen: So hat etwa Sören Kierkegaard die Klage Hiobs als Ausdruck seines Gottvertrauens gedeutet. Dazu: Welz, Vertrauen, 15-20.

${ }^{60} \mathrm{Im}$ Blick auf die praktische Theologie ist dieser Erweis nicht mehr nötig, vgl. I. Baldermann, Art. Klage, praktisch-theologisch, $\mathrm{RGG}^{4}$ IV (2001), $1392 \mathrm{f}$.
} 
Begriff „Ehre“ verbundenen Phänomene bieten sich unserer klagetheoretischen Abhandlung also als ein Plausibilisierungsfeld für den Aktualitätsbezug der Klage an. Die eben behauptete Relevanz des Themas „Ehre“ versteht sich freilich nicht von selbst, sondern muss erst noch freigelegt und ihrerseits plausibilisiert werden. Das führt dazu, dass wir methodisch zunächst einen längeren Zwischenschritt einschalten müssen (2. Kapitel), bevor wir den Aktualitätsbezug der Klage erheben können (3. Kapitel).

\section{Ehre, ein prekäres Phänomen auch der Spätmoderne}

Es graust den spätmodernen Menschen Europas, wenn er das Wort „Ehre“ schon nur hört. Schon in den Siebzigerjahren meinte der Soziologe Peter Berger, die Ehre sei in der Gegenwartsgesellschaft obsolet geworden, sie bezeichne nur noch einen Anachronismus. ${ }^{61}$ Zählt die Ehre nicht zu den längst überholten gesellschaftlichen Phänomenbeständen, die wir getrost und auch etwas erleichtert entsorgt haben und nie wieder recyclen möchten? Haben wir der durch die Ehre beförderten irrationalen Aufblähung der Verletzlichkeit im sozialen Verkehr $^{62}$ nicht längst den Abschied gegeben? Wäre es nicht besser auf alle Ehre zu verzichten? Ist sie doch latent gewalttätig, hatte ihre unerträglichen Ausläufer im Nationalsozialismus und ist eng mit der Geschichte der Diskriminierung der Frau verbunden bis hin zu den noch heute anzutreffenden schrecklichen Ehrenmorden. Warum also die Ehre noch einmal zum Gegenstand theologischen Nachdenkens machen, wo sie sich doch bestenfalls für kritische Nachrufe oder polemische Abgesänge eignet?

Nun deshalb, weil die Totgewünschte vielleicht gar nicht so tot ist. In den letzten Jahren sind vor allem in den USA zahlreiche Bücher von Philosophen, Politikwissenschaftlerinnen und Historikern erschienen, die bestreiten, dass der Ehre in der Moderne der Abschied gegeben wurde und dass ein solcher Abschied überhaupt möglich und wünschbar ist. Sie plädieren dafür, der Ehre eine höhere Aufmerksamkeit zu schenken, weil ihr eine zentrale soziale und moralische Bedeutung eignet. ${ }^{63}$ Der wohl bekannteste Intellektuelle in den USA, der sich dem Thema „Ehre“ angenommen hat, ist der Philosoph Kwame Anthony Appiah. In seinem 2010 erschienene Buch „The Honor Code“ schreibt er: „Wir mögen glauben, mit der Ehre abgeschlossen zu haben, aber die Ehre hat nicht mit uns abgeschlossen."64

Appiah zufolge spielte „Ehre“ bzw. spielten Ehrvorstellungen ${ }^{65}$ eine sehr wichtige Rolle in der Transformation überkommener, inhumaner „Ehrenwelten“ - wie Appiah sagt. ${ }^{66}$ Die Ehre

\footnotetext{
${ }^{61}$ P.L. Berger/B. Berger/H. Kellner, Das Unbehagen der Modernität, Frankfurt/New York 1975, vgl. darin den Exkurs: Über den Begriff der Ehre und seinen Niedergang, 75-85, der freilich am Ende über eine Wiederentdeckung der Ehre spekuliert und dies sogar für moralisch wünschenswert hält! - Auch nach Ute Frevert ist die Ehre, ,an den Rand des sozialen Gefühlsraums gerückt“. U. Frevert, Vergängliche Gefühle (Historische Geisteswissenschaften: Frankfurter Vorträge No. 4), Göttingen 2013, 17.

${ }^{62}$ Vgl. J.-P. Wils, Gotteslästerung, Frankfurt a.M./Leipzig 2007, 75f.

${ }^{63}$ Um nur ein paar wichtige Titel aus der neueren englischsprachigen Diskussion zu nennen: L.M. Johnson Bagby, Thomas Hobbes: Turning Point for Honor, New York 2009; Tony Cunningham, Modern Honor: A Philosophical Defense, New York 2013; L.M. Johnson/D. Demetriou (Eds), Honor in the Modern World: Interdisciplinary Perspectives, Lexington 2016; S.R. Krause, Liberalism with Honor, Cambridge u.a. 2002; P. Olsthoorn, Honor in political and moral philosophy, Albany 2015; R.L. Oprisko, Honor: A Phenomenology, New York 2012; W.L. Sessions, Honor For Us: A Philosophical Analysis, Interpretation and Defense, New York 2010. Instruktiv für die Vitalität der Diskurse: https://honorethics.org/category/philosophy-of-honor/ (Zugriff: 21.4.2017).

${ }^{64}$ K.A. Appiah, Eine Frage der Ehre, oder: Wie es zu moralischen Revolutionen kommt, München 2011, 18 . Vgl. auch: ders., A Decent Respect: Honour in the Life of People and of Nations, Hochelaga Lectures 2013-2014, ed. by $P$. Kapai, Hong Kong 2015.

${ }^{65}$ Appiah verwendet den Begriff der Ehre meist singularisch, mit bestimmtem Artikel und verzichtet darauf, ihn in Anführungszeichen zu setzen. Auch wir werden es im Folgenden aus praktischen Gründen so handhaben. Es ist darum wichtig, an dieser Stelle darauf hinzuweisen, dass damit kein essentialistisches Verständnis von ,der Ehre“ verbunden ist, sondern mit „Ehre“ diskursive Phänomene bezeichnet werden, deren kulturelle, soziale,
} 
fungierte als Treiber moralischer Revolutionen. Und diese Treiberfunktion hat auch heute nicht ausgedient. Glaubt man Appiah, so hat die Ehre ein kathartisches, demokratisches, weltbürgerlich offenes Potential für die Ablösung althergebrachter Hierarchien und Geschlechterrollen.

Uns geht es im Folgenden nicht um eine Darstellung und Aufarbeitung der neueren amerikanischen Diskurse zur Ehre als solcher, sondern lediglich darum, ihren Impuls für eine neue Aufmerksamkeit für das Thema „Ehre“ aufzunehmen und es anhand einer kleinen Phänomenologie so zu profilieren, dass im Anschluss daran die Relevanz der Klage im Blick darauf erhoben werden kann.

\subsection{Eine kleine Phänomenologie der Ehre}

Die kleine Phänomenologie soll in zwei Schritten entwickelt werden:

\subsubsection{Traditionelle Ehrformen}

Beginnt man, zwischen verschiedenen Formen der Ehre zu unterschieden, so zeigt sich, dass die Ehre kein Randdasein fristet, sondern auch in der europäischen Spätmoderne durchaus präsent ist.

Wohl ist hier die alte Standesehre, von der noch Georg Simmel und Max Weber handelten, weitgehend verschwunden. Oder sagen wir es genauer: Sie hat sich sozial zu den „feinen Unterschieden" verdünnt und wirkt in Lebensstilmilieus fort ${ }^{67}$. Doch stösst man nicht im Mittelmeerraum noch immer auf vitale Formen der Familienehre $?^{68}$ - selbst wenn man sie nicht mehr in der alten Gegenüberstellung von mediterraner „Schamkultur“ und nordeuropäischer „Schuldkultur“ deutet. ${ }^{69}$ Zudem: Lassen sich in unseren Breitengraden nicht beständige Formen der Berufsehre ${ }^{70}$ beobachten, etwa bei Ärztinnen, Pfarrern, Anwältinnen, Handwerkern und Wissenschaftlerinnen? Und gibt es nicht auch in unseren Gesellschaften immer noch so etwas wie die „Ehre der kleinen Leute“? Soziologen weisen zudem darauf hin, dass auch in Gefängnissen sehr ausgeprägte Ehrenkodizes vorherrschen. ${ }^{71}$ Sodann: Hält sich nicht die militärische Ehre in gewissen Kontexten mit erstaunlicher Beharrlichkeit? „Auch Deutschland hat eine Ehre!“72 - hat kürzlich Kanzleramtschef Altmaier die NaziVorwürfe von Recep Tayyip Erdogan gekontert. Das weist darauf hin, dass die Nationalehre nicht nur bei hohen Staatsbesuchen inszeniert wird, sondern auch in Zeiten der Globalisierung ein identitätsstiftendes Deutemuster bietet. Man muss sicher fragen, ob traditionelle Ehrkodizes im Internet überhaupt noch vorkommen und funktionieren. Doch warum gibt es dann so viele Klagen über Ehrverletzungen im Internet? Warum dann all die öffentlichen Beschämungspraktiken, die mittlerweilen im wenig schönen Bild des „shitstorms“ zusammengefasst werden? ${ }^{73}$ Schliesslich: Gehört die sexuelle Denunziation als

genderspezifische u.a. Festschreibungen nicht reproduziert, sondern vielmehr analysiert werden sollen, damit sich auch Möglichkeiten auftun, um sie kritisch zu verflüssigen.

${ }^{66}$ Appiah, Eine Frage, 36ff et passim.

${ }^{67}$ So auch L. Vogt, Zur Logik der Ehre in der Gegenwartsgesellschaft, Frankfurt 1997, 393.

${ }^{68}$ Vgl. L. Vogt/A. Zingerle, Einleitung, in: dies. (Hg.), Ehre. Archaische Momente in der Moderne, Frankfurt a.M. ${ }^{2} 2015,9-34,21$.

${ }^{69}$ So noch: J.G. Peristiany (Ed.), Honour and Shame: The Values of Mediterranean Society, Chicago 1966.

${ }^{70} \mathrm{Vgl}$. Vogt/Zingerle, Einleitung, 12.

${ }^{71}$ Vgl. R. Girtler, „Ehre“ bei Vaganten, Ganoven, Häftlingen, Dirnen und Schmugglern, in: Vogt/Zingerle (Hg.), Ehre, 222f.

${ }^{72}$ Zitiert nach einem Artikel in der NZZ (https://www.nzz.ch/international/streit-zwischen-tuerkei-und-eu-auchdeutschland-hat-eine-ehre-ld.151337 - Zugriff 22.5.2017).

${ }^{73}$ Vgl. dazu auch die Beobachtungen von K. Huizing, Scham und Ehre. Eine theologische Ethik, Gütersloh 2016, 179-232. 
Rufschädigung - ob berechtigt oder nicht - nicht zum gängigen Praxisinventar politischer Wahlprozesse? ${ }^{74}$

Die Liste der Beispiele könnte noch um ein Vielfaches verlängert werden. Bereits die kurze Aufzählung zeigt jedoch, dass wir auch im spätmodernen Europa immer noch in profilierten Ehrenwelten leben. Schliesslich ist $\mathrm{zu}$ bedenken, dass durch die verstärkten Migrationsbewegungen auch die Ehrformen vielfältiger werden - und mit ihnen die interkulturellen Irritationen zwischen den Ehrenwelten.

\subsection{Transformierte Formen der Ehre zwischen Prestige und Würde}

Doch die eben erwähnten traditionellen Formen der Ehre sollen nicht darüber hinwegtäuschen, dass sich die Ehrkodizes im 20. Jahrhundert erheblich transformiert haben. Wenn ich richtig sehe, so bewegt sich die Ehrsemantik in unserem Kontext innerhalb eines Bedeutungsspektrums, das durch die Pole Prestige/Ruhm/Status einerseits und Würde andererseits aufgespannt wird. ${ }^{75}$

Der Ehren-Pol „Prestige“ teilt mit den traditionellen Ehrformen die Exklusionsdynamik und die Tendenz zur gesellschaftlichen Hierarchisierung. Eine als Prestige verstandene Ehre ist aber nicht mehr an Stand oder Familie gebunden, sondern kompetitiv strukturiert. Zumindest theoretisch kann sich jedermann Prestige erwerben, man denke etwa an Sport oder Reichtum. Anders steht es mit dem zweiten Pol der Ehrsemantik, der Würde. Ich muss hier kurz ausholen:

In theoretischen Abhandlungen wird das Konzept der Ehre oft den traditionalen Gesellschaften zugeordnet, die auf Erhaltung sozialer Ungleichheit aus sind. Dagegen wird das Konzept der Würde den modernen, demokratischen Gesellschaften zugeordnet, die von einer prinzipiellen Gleichheit aller Menschen ausgehen. ${ }^{76}$ Gemäss dieser Einschätzung ist die Ehre moderneuntauglich. Denn sie hat die universalisierende und egalisierende Transformation nicht geschafft, die den Begriff der Würde kennzeichnet. Diese gängige Einschätzung ist zwar nicht falsch. Doch es gibt eben verschiedene Formen von Ehre. Und in der (spät)modernen Philosophie zeichnet sich eine Tendenz ab, die Ehre mit der Menschwürde wenigstens partiell konvergieren zu lassen. Wo das geschieht, wird oft zwischen externer und interner Ehre unterschieden und die interne Ehre als Integrität charakterisiert. ${ }^{77}$ Die interne Ehre hat also ein gewisses Universalisierungspotential und ist nicht mehr hegemonial bestimmt. Entsprechend wird dann auch betont, dass sich Ehre und humanistische Werte, Ehre und Demokratie ${ }^{78}$ gerade nicht ausschliessen, dass sich die Ehre mit Tugenden wie Ehrlichkeit, Vertrauenswürdigkeit, Dankbarkeit, Integrität, Respekt verbinden lasse.

Bestimmte Ehrformen scheinen also doch modernetauglich. Das phänomenale Feld der Ehre ist jedoch nicht leicht zu erfassen. Es präsentiert sich spätmodern in einer seltsamen Mischung aus althergebrachten und interkulturell akkumulierten, andererseits aber auch transformierten Formen von Ehre. Entsprechend ist es auch nicht leicht, eine Ehre-Definition zu geben. Es sei dennoch in aller Vorläufigkeit gewagt:

\footnotetext{
${ }^{74}$ So schon $F$. Koch, Sexuelle Denunziation. Ein Beitrag zur systematischen Ehrabschneidung in der politischen Auseinandersetzung, in: Vogt/Zingerle (Hg.), Ehre, 117-131.

${ }^{75}$ In dieser Hinsicht dürfte Appiah recht behalten mit seiner Unterscheidung zwischen einer kompetitiven, hierarchischen Ehre im Sinne der Wertschätzung und einer an der Würde orientierten Ehre im Sinne des Anerkennungsrespektes, vgl. Appiah, Eine Frage, 191-193. Zur Transformation der Standesehre zum Sozialprestige vgl. auch Vogt/Zingerle, Einleitung, 9f, und A. Honneth, Kampf um Anerkennung. Zur moralischen Grammatik sozialer Konflikte, Frankfurt a.M. ${ }^{8} 2014$ (1992), $203 \mathrm{f}$.

${ }^{76}$ So z.B. Wils, Gotteslästerung, 58. 61, oder Honneth, Kampf, 204.

77 Diese philosophischerseits durchaus gängige Unterscheidung vertreten in neueren Debatten z.B. Oprisko, Honor, 120ff, oder M. Honecker, Art. Ehre II., RGG ${ }^{4}$ II (1999), 1104.

${ }_{78}$ Man spricht sogar von "democratic honor": Olsthoorn, Honor, 32ff et passim.
} 
„Ehre“ bezeichnet ein gemeinschaftsrelatives, kulturell und historisch variables Wertschätzungs- und Anerkennungsverhältnis, das sich in der Interaktion von Selbst- und Fremdzuschreibungen aufbaut und sowohl für Individuen wie Kollektive identitätsstiftend ist. Ehre ist ein emotional aufgeladener, machtförmiger ,soziale(r) Ordnungsfaktor ersten Grades " "79.

Ehre reguliert auch das Geschlechterverhältnis, Ehre ist sichtbar, sie wird oft mit besonderen Insignien, Gesten und Ritualen markiert. Denn bei der Ehre geht es nicht nur um ein internalisiertes, sondern oft auch sehr äusserliches, körperbezogenes „Ansehen“. Ehre ist kontextrelativ. Sie gilt nicht überall, sondern jeweils nur innerhalb einer bestimmten Ehrenwelt, die durch einen spezifischen Ehrenkodex konfiguriert wird. Wir leben aber nicht nur je in einer Ehrenwelt, sondern wir bewohnen gleichzeitig mehrere Ehrenwelten, teilweise stehen sie lose nebeneinander, stehen in Konkurrenz oder werden durch eine Ehrenwelt dominiert.

Dieser kleine Überblick über das Phänomen der Ehre und die neueren amerikanischen Diskurse bildete eine Hinführung zur Beantwortung der Frage, um die es nun gehen soll. Nämlich die Frage, inwiefern die Klage auf das skizzierte Phänomenfeld der Ehre beziehbar ist und worin (in einem jüdisch-christlichen Kontext) dabei ihre Bedeutung liegt.

\section{Ehre und Klage}

Das Alte Testament kennt ein vielfältiges Reden von „Ehre“. Neben den selteneren Begriffen

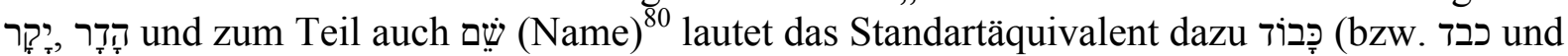
seine Derivate), das man in einem physikalischen Sinn als Gewichtigkeit, in einem geistigen Sinne als Wichtigkeit bzw. Ehre, Herrlichkeit, Glanz übersetzen kann. Wir verzichten hier bewusst darauf, im Blick auf das Alte Testament die sich zum Teil auch in der deutschen Sprache überschneidenden Begriffe Ehre und Herrlichkeit zu unterscheiden. Sie lassen sich in den althebräischen Texten kaum auseinanderhalten. ${ }^{81}$ Im Blick auf Gott bezeichnet כָּ כeine Ehre und Königsherrlichkeit hinsichtlich seiner Schöpfung, der Chaosmächte und Naturgewalten, den Göttern, Königen und Völkern (vgl. Ps 19,2; 24,7-10; 29,1-3; 97,6f; 102,16f). Gottes כָּבוֹ nimmt im Tempel Wohnstatt (Ps 26,8; 29,9) und erfüllt die ganze Erde (Ps 72,19; 85,10; Jes 6,3). ${ }^{82}$

Für unseren Zusammenhang sind nun insbesondere die Aussagen zur menschlichen Ehre interessant. Es ist hier natürlich nicht möglich, die Breite und Vielfalt der Ehrphänomene wiederzugeben (zu denen auch Phänomene wie Scham und Schande als Kehrseiten von bestimmten Ehrformen gerechnet werden müssten ${ }^{83}$ ) und ihre Bedeutungstiefe zu ermessen.

\footnotetext{
${ }^{79}$ Vogt, Zur Logik, 23.

${ }^{80}$ Vgl. J. Dietrich, Über Ehre und Ehrgefühl im Alten Testament, in: B. Janowski/K. Liess, Der Mensch im Alten Israel. Neue Forschungen zur alttestamentlichen Anthropologie (Herders Biblische Studien 59), Freiburg u.a. 2009, 419-452, 436f.

81 So auch: A. Wilke, Art. Ehre/Herrlichkeit, in: WiBiLex, https://www.bibelwissenschaft.de/wibilex/dasbibellexikon/lexikon/sachwort/anzeigen/details/ehre-herrlichkeit/ch/6492e846b62e0703f9ee229f254b767b/ (Zugriff 7.3.2017)

${ }^{82}$ Vgl. Wilke, Art. Ehre/Herrlichkeit, sowie ausführlicher: M. Weinfeld, Art. דָָּּּ, Theologisches Wörterbuch zum Alten Testament, Stuttgart u.a. 1973ff.

${ }^{83}$ In der exegetischen Literatur werden diese Begriffe oft auch gemeinsam reflektiert. Z.B. Dietrich, Über Ehre, 410-452; B. Janowski, Anerkennung und Gegenseitigkeit. Zum konstellativen Personbegriff des Alten Testaments, in: Janowski/Liess, Der Mensch, 181-211, bes. 183f.196-200; N. Chibici-Revneanu, Art: Ehre/Scham/Schande, in: WiBiLex, https://www.bibelwissenschaft.de/wibilex/dasbibellexikon/lexikon/sachwort/anzeigen/details/ehre-scham-schandent/ch/cd45951981187dd18a96902e57eadc7b/ (Zugriff 13.3.2017). Zum Begriff der Scham: T. Krüger, „Schäm dich (nicht)!“. Anmerkungen zu Scham, Schande, und Schuld in der Hebräischen Bibel, in: Hermeneutische Blätter 1/2 (2015), 86-109.
} 
Nur soviel sei festgehalten: Mit dem Begriff der Ehre steht im Alten Testament ein sozialanthropologischer Grundbegriff ${ }^{84}$ zur Debatte. Das alttestamentliche Menschenbild lässt sich - grob gesagt - mittels eines konstellativen Personbegriffes beschreiben, gemäss dem Leibsphäre und Sozialsphäre einander entsprechen und verbunden sind. Dabei wird der menschliche Leib als konstellative, aus einzelnen Gliedern zusammengesetzte Ganzheit verstanden und das Subjekt dieses Leibes ist kein isoliertes Ich, sondern durch Konnektivität charakterisiert (d.h. Einbundenheit des Einzelnen in eine soziale Gemeinschaft, die die Grundlage des Zusammenlebens bildet). ${ }^{85}$ Das durch die Pole „Ehre - Schande“ aufgespannte Integritätsspektrum bezieht sich primär auf die Sozialsphäre - wenngleich es nie von der Leibsphäre losgelöst gedacht werden darf, geht es bei der Ehre bzw. Schande doch nicht nur um ein internalisiertes, sondern oft auch sehr äusserliches, körperbezogenes „Ansehen“686.

\subsection{Ehre in den alttestamentlichen Klagepsalmen}

Für unser Anliegen reicht es, zwei anthropologische Phänomenbereiche herauszugreifen und im Blick auf das Klagegebet zu profilieren:

1. Wie sich den alttestamentlichen Texten entnehmen lässt, folgen soziale Anerkennungsverhältnisse hochkodierten, komplexen (und auch nicht einheitlichen!) gesellschaftlichen Mustern. „Ehre“ zeigt sich als ein sehr fragiles Relationsgefüge, das schnell zusammenbrechen kann. Im Kontext der Psalmen werden die weltförmigen Kräfte, die dem Beter seine Ehre rauben, ihn in seiner Ehre verletzen oder bedrängen als „Feinde“ bezeichnet. So heisst es etwa im Klagelied Ps 7: ,so verfolge mich der Feind und hole mich ein, trete zu Boden mein Leben und lege in den Staub meine Ehre" ${ }^{687}$ (Vers 6). Und in Ps 4,3 klagt ein Beter: „Ihr Mächtigen, wie lange noch bleibt meine Ehre geschändet, wollt ihr Nichtiges lieben, auf Lügen sinnen?“

Im Blick auf die Selbstverfluchung des Beters in Ps 7,6 wird man von einem totalen Ehrverlust, wenn nicht im Sinne des physischen, so doch sicher des ,sozialen Todes“ sprechen müssen. ${ }^{88}$ Während es sich in Ps 4,3 um die Missachtung und Ausbeutung eines Armen durch Reiche geht. ${ }^{89}$

Die beiden zitierten Verse machen exemplarisch deutlich, wie in der Klage ${ }^{90}$ Raum geöffnet wird, um Ehrverlust oder Ehrverletzung zur Sprache zu bringen. Die Klage ermöglicht es, ehrbezogene Leidenserfahrungen ungefiltert zu benennen. Es gibt keine Gebetsform, in der so authentisch um Fassung und Worte gerungen wird, wie in ihr. Eine zeitgenössische theologische Würdigung der Klage wird ihr signifikantes „Mehr“ an Sprache $^{91}$ auch auf

\footnotetext{
${ }^{84}$ So im Blick auf Ps 30,13: Janowski, Konfliktgespräche, 282.

${ }^{85} \mathrm{Vgl}$. Janowski, Konfliktgespräche, 43.46-52.110., zum Begriff der Konnektivität: 24.52.188.202f.

${ }^{86}$ Viele Formen der Ehre sind der Leiblichkeit eingeschrieben bzw. werden an ihr manifest werden. Zu Recht spricht Jan Dietrich von einer „Leibesehre“. Ders., Über Ehre, 422 u. ff. - Zu fragen wäre, ob dem oben genannten Spektrum „Ehre - Schande“ ergänzend ein Spektrum „Ehre - Scham“ zur Seite gestellt werden müsste, das sich stärker auf die Leibsphäre bezieht.

${ }^{87}$ Hier und im ff zit. nach: Zürcher Bibel, Zürich 2007.

${ }^{88} \mathrm{Zu}$ Form und Hintergrund dieser Selbstverfluchung vgl. Janowski, Konfliktgespräche, 145-147, zum ,,sozialen Tod“: ebd., 47f. - Eine klimaktische Zusammenstellung der Missachtungsformen durch „die Feinde“ in den Klageliedern findet sich ebd., 198.

${ }^{89}$ Für eine soziale und nicht theologische Deutung der Ehre in Ps 4,3 plädiert Erich Zenger in: F.-L. Hossfeld/E. Zenger, Die Psalmen I. Psalm 1-50, Die Neue Echter Bibel. Kommentar zum Alten Testament mit der Einheitsübersetzung, Würzburg 1993, 59. Für diese Deutung sprechen auch die sozialen Konnotationen des Ehrbegriffes in den Nachbarpsalmen 3,4; 7,6; 8,6 (ebd., 59).

${ }^{90}$ Ps 4 gehört im Unterschied zu Ps 7 nicht zur Gattung des Klageliedes des Einzelnen, bietet aber in V3 als Klageelement eine Anklage der Mächtigen vor Gott.

91 Ähnlich formulieren Gross/Kuschel, „Ich schaffe Finsternis“, 202. Zur Spracharbeit mit der Klage in der Seelsorge vgl. F. Lienhard/A. Bölle, Zur Sprache befreit - Diakonische Christologie (Theologische Anstösse 5),
} 
Verluste und Verletzungen der oben im 2. Kapitel genannten vielfältigen Formen der Ehre beziehen müssen. Es bleibt freilich festzuhalten, dass diese Applikation differenziert gedacht werden muss, nicht nur im Blick auf die Verschiedenheit der Ehrformen, sondern auch im Blick auf die Intensität der Einwirkung auf sie. Denn die Erfahrung einer Entehrung durch massive physische Gewalt (die mit einer Traumatisierung einhergehen kann, bei der es neurophysiologisch zur partiellen Ausschaltung des Sprachzentrums kommt) wird zunächst wohl nur in einem Mitbeten einer stellvertretend gesprochenen Klage oder in einem Nachbeten vorgeprägter Klagegebete bestehen können, während sich zum Beispiel im Falle von weniger leibbezogenen, beschämenden Anfeindungen den Betenden im Vollzug des Betens leichter Sprachräume erschliessen und öffnen, um ihre Ehrverletzungen anzusprechen.

2. Klagegebete bieten und generieren aber nicht nur einen intimen, geschützten Sprachraum, um Entehrungen, Ehrverletzungen und Bedrohungen der eigenen Ehre zu benennen. Sie zeugen auch von einer ganz anderen Ehre, die die verletzte oder bedrängte Ehre transzendiert. Entscheidend dafür ist der Gottesbezug der Klagegebete. ${ }^{92}$ So heisst es etwa im Klagegebet Ps 3,2-4: „HERR, wie zahlreich sind meine Feinde, viele sind es, die gegen mich aufstehen, viele, die von mir sagen: Er hat keine Hilfe bei Gott. Du aber, HERR, bist mir Schild, bist meine Ehre und erhebst mein Haupt." Die Vertrauensäusserung in Vers 4 zeigt, dass der Beter seine Ehre nicht über die Anfeindungen seiner Frömmigkeit definiert, sondern ganz in die Gottesbeziehung hineinverlegt. Die Transzendierung der verletzten und bedrängten Ehre geschieht also nicht durch ein mirakulöses Ungeschehenmachen der Infragestellung der Ehre oder eine simple restitutio früherer Ehrverhältnisse. Sie geschieht vielmehr so, dass sich der Bedrängte im Gebet an Gott wendet und im Rahmen dieser Intensivierung der Gottesbeziehung seine Ehre ganz Gott überantwortet. Die Transzendierung manifestiert sich in einer neuen Erschlossenheit Gottes als der Ehre des Beters im Blick auf die Gegenwart (Ps 3,4 vgl. ähnlich Ps 62,8) und die Zukunft (Ps 73,24).

Diese theologische Deutung der Ehre ist anspruchsvoll. Ihre historische Herkunft ist hier nicht zu klären. Versucht man sie aus einer systematisch-theologischen Sicht zu rekonstruieren, so beruht sie auf mindestens zwei Prämissen: Auf der gedanklichen Voraussetzung, dass erstens Gott selbst das Prädikat der Ehre beigelegt wird (vgl. Ps 24,7-10; 29,1-3) und diese Ehre auch darin besteht, den (sündigen) Menschen zu retten (Ps 79,9), und dass zweitens die Ehre als Gabe Gottes an den Menschen verstanden werden kann (Ps 8,6; 84,12, vgl. Ps 91,15). Aufgrund dieser Rekonstruktion lässt sich die Aussage in Ps 3,4, dass Gott die Ehre des Beters ist, im Sinne einer Selbstgabe Gottes deuten, dessen Wesen Ehre und Herrlichkeit ist. Diese partizipative Relationsstruktur der Ehre macht es dann auch nachvollziehbar, dass selbst die Klagegebete dazu auffordern, Gott im Lob die Ehre zurückgeben (Ps 22,24), und dass die eigene Ehre gleichsam als Organon Gottes im Menschen für Gott zu musizieren beginnt: „Du hast meine Trauerklage gewendet zum Reigentanz für mich, du hast mein Trauergewand gelöst und mich mit (einem) Freude(ngewand) umgürtet, damit ,meine“ Ehre für dich musiziert und nicht schweigt." "93 (Ps 30,12f, vgl. 16,9)

Unsere Ausführungen machen deutlich, dass im Psalter ein Glaubenswissen überliefert wird, gemäss dem der verletzten oder bedrängten zwischenmenschliche Ehre im Kontext von Klageaussagen ein Verständnis von der Partizipation an der Ehre Gottes gegenüberstellt wird,

Neukirchen-Vluyn 2013, 195-197; vgl. auch: K. Augst, Auf dem Weg zu einer traumagerechten Theologie. Religiöse Aspekte in der Traumatherapie - Elemente heilsamer religiöser Praxis (Praktische Theologie heute 121), Stuttgart 2012, 188f.

92 Sofern für die Gebetsgattung der Klage die Reziprozität von Weltbezug (Feind), Selbstbezug (Beter) und Gottesbezug (JHWH) konstitutiv ist (Janowski, Konfliktgespräche, 42.), ist es nur folgerichtig, dass in ihr die feindliche Bedrohung der Ehre, Ehrverletzung oder Ehrverlust stets im Horizont der Gottesbeziehung verhandelt werden.

${ }^{93}$ Übersetzung: Janowski, Konfliktgespräche, 271. 
das menschliche Ehrkodizes notwendig transzendiert und so heilsam relativiert. Aufgrund dieser Gegenüberstellung werden wir weiter unten von einer paradoxen Ehre Gottes reden.

Wir hatten oben gefragt, inwiefern die Klage auf das skizzierte Phänomenfeld der Ehre beziehbar ist und worin dabei ihre Bedeutung liegt. Auch wenn wir uns in unseren Ausführungen nur auf wenige Andeutungen beschränken konnten, erlauben sie doch wenigstens thetisch folgende Antwort zu formulieren: Die Klage bildet einen ausgezeichneten spirituellen Kontext 1. zur Benennung von Ehrverlusten und Ehrverletzungen und 2. zu deren religiöser Verarbeitung, sofern sie die in Frage stehenden Ehrenkodizes heilsam zu transzendieren hilft. Die Gebetsform der Klage leistet damit einen wichtigen Beitrag zur Konstitution ethischer Dispositionen im betenden Subjekt, denn sie ermächtigt einerseits zum Widerstand gegenüber Ehrverletzungen (empowerment ${ }^{94}$ ) und hebt andererseits die Schwelle gewaltförmiger Reaktionen (Gewaltverzicht ${ }^{95}$ ) der Verletzten und Gedemütigten (was im Blick auf das latente Gewaltpotential von Ehrverletzungen durchaus erheblich ist)!

Die eben skizzierte Bedeutung der Klage hat den Status eines Glaubenswissens und erschliesst sich nur aus einer jüdisch-christlichen Perspektive. ${ }^{96}$ Diese Perspektivität ist gerade im Blick auf die Ehrenthematik nichts Aussergewöhnliches. Denn zu den Einsichten einer spätmodernen Phänomenologie der Ehre gehört, dass wir immer schon kontextrelativ und in unterschiedlicher Intensität gleichzeitig an verschiedenen Ehrenwelten partizipieren. Zur Besonderheit der jüdisch-christlichen Tradition darf jedoch gerechnet werden, dass sie sich im Laufe ihrer Entwicklung nicht nur mit verschiedenen Ehrenwelten amalgamiert und neue Ehrenwelten hervorgebracht hat, sondern $\mathrm{zu}$ diesen letzteren potentiell immer auch ein Wissen gehört hat, dass sie durch die ganz andere Welt der Ehre Gottes transzendiert und transformiert und also neu konfiguriert werden können und müssen. Dieser Gedanke soll in den folgenden Abschnitten vertieft werden.

\subsection{Zur paradoxen Ehre im Neuen Testament}

Die beiden exemplarisch aufgewiesenen Funktionen der Klage im Blick auf die Ehre, also die Benennungs- und Transzendierungsfunktion, lassen sich auch im Neuen Testament beobachten. Ohne einen einlinigen Traditionszusammenhang behaupten $\mathrm{zu}$ wollen, sei im Folgenden kurz angedeutet, wie die beiden Funktionen hier in gewisser Weise eine Fortsetzung finden.

Zur Funktion der Benennung von Ehrverlust, Ehrverletzungen:

Zwischenmenschliche Ehrbezeugungen gegenüber Jesus finden sich in den Evangelien abgesehen vom seinem königlichen Einzug in Jerusalem (Lk 19,38, mit Erinnerung an Lk 2,14) kaum. Vielmehr wird seine Passionsgeschichte etwa im Markusevangelium in Kapitel 14 und 15 als unüberbietbare Entehrungsgeschichte inszeniert. ${ }^{97}$ Die Passion Jesu trägt alle Zeichen der Ehrlosigkeit: die zunehmende soziale Isolation Jesu, der Vorwurf der Gotteslästerung, die Freilassung eines Mörders an seiner Stelle, die Misshandlungen und die

\footnotetext{
${ }^{94}$ Ingo Baldermann versteht die in der Klage vollzogene Versprachlichung individuell auswegloser, emotional aporetischer Lebenserfahrungen als einen Schritt innerer Befreiung und spricht von einem „Akt des wieder erwachenden Selbstbewußtseins (empowerment).“ Baldermann, Art. Klage, 1392.

95 An dieser Stelle zeigen sich Parallelen zur Möglichkeit eines Racheverzichtes in den sog. Fluch- und Rachepsalmen (Ps 58; 59; 69; 70; 109 u.ö.). Dazu: Janowski, Konfliktgespräche, 129-133. - Wobei natürlich nicht übersehen werden kann, dass es im Psalter auch Stimmen gibt, die die Rache selber oder unter Mitbeteiligung an der Rache Gottes vorsehen (Ps 18,48; 58,11; 14,7).

${ }^{96}$ Natürlich liefert auch schon eine rein historische Untersuchung der Ehrverständnisse in den Klagegebeten einen wichtigen historischen Beitrag zum besseren Verstehen des Phänomens „Ehre“. Doch darauf liegt in unserem systematisch-theologisch angelegten Zugang nicht der Fokus.

${ }^{97}$ Darauf hat neben Anderen hingewiesen: Janowski, Konfliktgespräche, 199.
} 
Verspottung mit Purpurmantel und Dornenkrone als „König der Juden“ durch die Soldaten, später seine Verspottung am Kreuz durch die Vorübergehenden, und die lästernden Hohepriester und Schriftgelehrten - ja selbst durch die neben ihm mitgekreuzigten Räuber; und schliesslich sein Verbrechertod am Kreuz, an einem öffentlichen Schandpfahl ausserhalb der Stadt. All das zeigt: aus der Sicht des Markusevangeliums starb Jesus auch den „,sozialen Tod" radikalster Ehrlosigkeit.

Das Markusevangelium erzählt die Passion Jesu in intensivem Rekurs und durch mehrfache Anspielungen auf die Psalmen. Im Hintergrund des Kreuzigungsberichtes (Mk 15,20b-41) stehen dabei mehrfache Referenzen auf das Klagelied Ps 22,2-22, die in gegenläufiger szenischer Anordnung in die Erzählung verwoben werden ${ }^{98}$ und in Jesu Klage: „Mein Gott, mein Gott, warum hast Du mich verlassen?“ (Mk 15,34) ihren Höhepunkt erreichen. Jesu Klage markiert und benennt also gleichsam die abgründige Spitze seiner Ehrlosigkeit: seine Gottverlassenheit! ${ }^{99}$

Zur zweiten Funktion der Transzendierung:

Die neutestamentliche Überlieferung kennt jedoch nicht nur jene markinische (und matthäische) Deutung des Todes Jesu im Sinne radikalster Ehrlosigkeit. Dieser am Evaluationsmassstab menschlicher Ehrkodizes orientierten Sichtweise kontrastiert nämlich eine Perspektive, die die Ehrlosigkeit Jesu christologisch neu vermisst:

Während die Herrlichkeit bzw. die Ehre Gottes (griech. $\delta$ ó $\xi \alpha^{100}$ ) in Aussagen wie Act 3,13 oder 1 Petr 1,11.21 auf Christi Auferweckung und Inthronisation bezogen ist, fällt auf, dass bei Paulus auch im Blick auf das Kreuz Jesu Christi von $\delta$ ó $\xi \alpha$ geredet wird (1 Kor 2,8, vgl. 2 Kor 4,6). Doch erst im Johannesevangelium wird die $\delta o ́ \xi \alpha$ Gottes prononciert mit dem Leiden und dem Kreuzestod Jesu Christi verknüpft. Nicht erst in seiner Auferweckung von den Toten und im nachösterlichen Wirken, sondern schon in seiner Passion, in seinem Kreuzestod wird Jesus verherrlicht (Joh 12,23.41;13,31f; 17,4) ${ }^{101}$. Die johanneische Darstellung bindet die $\delta$ ó $\xi \alpha$ narrativ unmittelbar an die Stunde der Passion Jesu und spricht von seiner Verherrlichung nicht allein hinsichtlich der Überwindung des Todes, sondern bereits im Blick auf den Weg des irdischen Jesus in den Tod. ${ }^{102}$ Gemäss der johanneischen Deutung wird also das Kreuz zum Ort der Präsenz der Ehre Gottes. ${ }^{103}$

\footnotetext{
${ }^{8}$ Vgl. Mk 15,24 - Ps 22,19, Mk 15,29 - Ps 22,8, Mk 15,30f - Ps 22,9, Mk 15,34 - Ps 22,2. Vgl. zur Psalmenrezeption in der Markuspassion die gute Übersicht bei Janowski, Konfliktgespräche, 355-365.

${ }_{99}$ Das Psalmzitat in Mk 15,34 ist weder im Sinne einer präfigurierten Auferweckungshoffnung (wie einige Exegeten unter Hinweis auf das Ende von Ps 22 annehmen) noch im Sinne eines nackten Verzweiflungsschreis zu deuten. Jesus richtet seinen Gottverlassenheitsschrei - wenn auch ohne antizipierte Rettungsgewissheit - noch immer als Klagegebet an Gott. Eine ähnliche Mittelposition vertritt Janowski, Konfliktgespräche, 360-365, bes. 364.

${ }^{100}$ Im Neuen Testament ist es v.a. der Begriff der $\delta o ́ \xi \alpha$, der (neben dem selteneren Begriff der $\tau \mu \eta \tilde{)}$ ) dem Begriff der Ehre/Herrlichkeit entspricht und via Septuaginta die Bedeutungsbeite des alttestamentlichen Begriffes aufnimmt. Wobei hier anders als im griechischen Profangebrauch die Bedeutung „Ehre, Ansehen“ zurücktritt

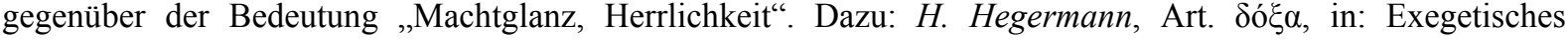
Wörterbuch zum Neuen Testament, hg. v. H. Balz/G. Schneider, Stuttgart 1980, 833f. Für eine präzisere Begriffsanalyse im Blick auf die profane Gräzität und das jüdisch-christliche Schrifttum vgl. N. ChibciRevneanu, Die Herrlichkeit des Verherrlichten. Das Verständnis der $\delta$ ó $\xi \alpha$ im Johannesevangelium (WUNT 231/2. Reihe), Tübingen 2007, 335-510.

${ }^{101}$ In dieser kreuzestheologischen Zuspitzung liegt ein Proprium johanneischer Theologie. Vgl. dazu: J. Frey, „,.. dass sie meine Herrlichkeit schauen“ (Joh 17,24). Zu Hintergrund, Sinn und Funktion der johanneischen Rede von der $\delta$ ó $\xi \alpha$ Jesu, in: ders., Die Herrlichkeit des Gekreuzigten. Studien zu den Johanneischen Schriften I, hg. v. J. Schlegel, Tübingen 2013, 639-662 (erstmals veröffentlicht: NTS 54 (2008), 375-397). Vgl. auch ChibciRevneanu, Die Herrlichkeit, zusammenfassend 508.

${ }^{102} \mathrm{Vgl}$. Frey, „Herrlichkeit“", 655 f.

${ }^{103}$ Ich setze exegetisch voraus, dass mit dem Begriff der $\delta o ́ \xi \alpha$ im Johannesevangelium in verschiedener Weise auch die Ehrensemantik mitschwingt. Vgl. Chibci-Revneanu, Die Herrlichkeit, 508-510.
} 
Die Aussagen von Johannes gewinnen zusätzlich an Schärfe, wenn man sich vor Augen hält, dass bei seiner kreuzestheologischen Zuspitzung der $\delta$ ó $\xi \alpha$ der jesaianische leidende Gottesknecht im Hintergrund steht ${ }^{104}$. Ultimative Brisanz gewinnen sie aber, wenn man sie in einer intertextuell-kanonischen Lektüre mit den skizzierten Aussagen des Markusevangeliums zusammenliest. Erst eine solche Lektüre offenbart die ganze neutestamentliche Zumutung, die Ehrlosigkeit des Gekreuzigten als Ort der Ehrenbezeugung bzw. des Herrlichkeitserweises Gottes zu glauben. Hier zeigt sich eine gesteigerte Form theologischer Transzendierung zwischenmenschlicher Ehre, gemäss der die menschliche Ehre nicht nur auf die göttliche Ehre hin überstiegen wird (wie etwa in Ps 3,4), sondern nach der dabei die göttliche Ehre zugleich mit dem radikal entehrten Jesus identifiziert wird.

Unsere Darlegung macht deutlich, dass sich auf dem Boden alttestamentlich-jüdischer Überlieferungen, zu denen u.a. auch die Klagegebete gehören, neutestamentlich an der Person Jesu eine sehr eigentümliche, christologische Präzisierung der Vorstellung der Ehre Gottes herausgebildet hat. Im Blick auf ihre ausserordentliche Logik könnte man von einer paradoxen Ehre sprechen. „Para - dox“ ist diese Ehre deshalb, weil sie alle herkömmlichen Evaluationsmassstäbe unterläuft und quer zu den gängigen Konzepten von der $\delta o ́ \xi \alpha$ steht: Sie steht quer sowohl im Blick auf die gängigen Vorstellungen von der Ehre Gottes, denn dieser Gott identifiziert sich mit dem Ehrlosen schlechthin. Sie steht aber auch und zuerst quer im Blick auf alle zwischenmenschlichen Ehrenkodizes, nach deren Evaluationsmassstab es sich bei der $\delta$ ó $\xi \alpha$ Christi um nichts als Torheit und Skandal handelt. ${ }^{105}$ (Wobei es bei der paradoxen Ehre nicht einfach um eine Verherrlichung radikaler Entehrung als solcher geht, sondern um die Verherrlichung des Entehrten im Tod und in der Auferweckung.) Abschliessend ist kurz über die aktuelle Bedeutung der paradoxen Ehre für den heutigen Menschen nachzudenken.

\subsection{Zur theologisch-anthropologischen und ethischen Bedeutung der paradoxen Ehre}

Der Gedanke der paradoxen Ehre impliziert soteriologisch, dass es keine menschliche Entehrung gibt, keine noch so massive Schmach und Schändung des Humanen, keinen sozialen Tod, der nicht von Gottes Ehre umfangen wäre. Es gibt keine menschlichen Abgründe, in die Gottes Ehre nicht hinabreichte um den Menschen auf seine Weise ehren. Die gottebenbildliche Ehre des Menschen (Ps 8,6) wird durch die paradoxe Ehre Gottes also erneuert und zugleich überboten. Wo sich dem Glauben die christologische Figur der paradoxen Ehre erschliesst, findet eine Umcodierung, Neuperspektivierung und Rekonfiguration aller menschlichen Ehrformen statt. Die paradoxe Ehre schliesst zwar nicht aus, dass Menschen nach menschlichen Massstäben zu Ehren gelangen. Durch die paradoxe Ehre wird aber doch eine kritische Ordnung etabliert, die unweigerlich zu nachhaltigen Irritationen gängiger Ehrenwelten und ihrer Kodizes führt. Das gilt im Blick auf unsere heutige Situation besonders für die traditionellen Ehrformen. Die Irritationen gelten aber auch den prestigeorientierten Ehrformen. Denn die paradoxe Ehre irritiert alle Ehrformen in der ihnen entsprechenden Weise. Sie negiert sie aber nicht alle. Denn sie hat das Potential, humane Ehrformen (die ja auch inhuman sein können), nicht nur zu verwandeln, sondern auch von ihrer Inhumanität zu befreien.

\footnotetext{
104 Jörg Frey macht die kreuzestheologische Zuspitzung der Herrlichkeitsaussagen bei Johannes u.a. an seinem Bezug auf Jesaia in Joh 12,41 deutlich, wobei er unterstreicht, dass es bei der Herrlichkeitsschau des Jesaia in johanneischer Perspektive nicht nur um die Tempelvision, sondern auch um die Herrlichkeit des leidenden Gottesknechtes (Jes 52,13, LXX) geht. Vgl. Frey, „Herrlichkeit“, 648-650.

${ }^{105}$ Klaas Huizing sieht in Jesus von Nazareth den grossen „Entschämer“, der für einen Statusverzicht plädiert (Gerd Theißen) und die kompetitiven Elemente am Ehrbegriffes abgeschliffen hat. In diesem Sinne liest er dann auch Gal 3,28. Huizing, Scham, $111 \mathrm{f}$.
} 
Eine weitere Eigenart der christologischen Figur der paradoxen Ehre besteht darin, dass sich mit ihr die Vorstellung eines Ehrenzuspruchs verbindet. Die paradoxe Ehre operiert gleichsam im Medium des unbedingten Ehren-Zuspruchs Christi. Inhumane Ehrenwelten beginnen erst da zu bröckeln, wo ihre Mitglieder zu neuen Ehren kommen - das lässt sich schon bei Appiahs moralischen Ehrrevolutionen beobachten. Dass die paradoxe Ehre bestehende Ehrformen so irritiert, dass dabei zugleich Ehre zugesprochen wird, macht sie zu einer närrischen Ehre. Sie ist eine närrische Ehre, weil sie den Menschen, den sie demaskiert, nicht blossstellt und beschämt, sondern als das entlarvt, was er im Spiegel Jesu Christi von Gott her immer schon ist: nämlich der wider all seine sündigen Abgründe geehrte, königliche Mensch! $!^{106}$

Worin liegt die Bedeutung einer theologischen Rekonstruktion jener paradoxen Ehre? Reicht es nicht, wenn wir uns an das Konzept der Menschenwürde halten, das doch ebenso gegen inhumane Ehrformen in Anschlag gebracht werden kann? Das Problem des modernen Würdekonzeptes besteht darin, dass ihm aufgrund seiner Universalisierbarkeit und seines prinzipiellen Egalitarismus notgedrungen eine hohe Abstraktheit eignet. Eine Abstraktheit, die im Blick auf den zwischenmenschlichen Umgang eine hermeneutisch doch recht anspruchsvolle, einseitig kognitive Anerkennungsökonomie voraussetzt, und die Würde zum blutleeren Superprädikat macht, das nicht imstande ist, ,alle Dimensionen der sozialen Wertschätzung in sich aufzunehmen " ${ }^{\text {107. }}$. Es ist unbestreitbar: Das Konzept der Menschenwürde gehört unhintergehbar zum Kernbestand einer jeden Ethik in der Theologie. Doch ebenso unhintergehbar muss auch die narrativ vermittelte, tiefer im Affekthaushalt verwurzelte und mit thymotischen Energien aufgeladene christologische Figur der paradoxen Ehre dazu gehören - und die durch sie irritierten, von Inhumanität befreiten Ehrformen. ${ }^{108}$ Aus theologischer Sicht wird man dem Konzept der paradoxen Ehre gegenüber dem der Würde insofern eine herausgehobene Stellung zuordnen müssen, als sich in ihm Universalität und Egalität mit dem narrativ konkretisierbaren Zuspruch verbinden, dass die Ehre Gottes ohne Unterschied jeden Menschen auf seine Weise ehrt und ihn so ermächtigt, für seine Ehre und die Ehre Anderer einzustehen. Gerade zur lebensweltlichen Sicherung des Postulates von der unantastbaren Menschenwürde bedarf es auch des weisheitlichen Glaubenswissens um die paradoxe Ehre Gottes. - Es steht auch im deutschsprachigen Raum eine kritische Neuvermessung des Konzeptes der Ehre für die Ethik im allgemeinen ${ }^{109}$ und für die Ethik in der Theologie ${ }^{110}$ im Besonderen an.

\subsection{Rückblick}

\footnotetext{
${ }^{106}$ Mit dem Begriff des königlichen Menschen wird hier auf die ursprüngliche Zusprechung der Königsehre in Ps 8,6 angespielt. Der Begriff erinnert zugleich an eine wichtige - freilich christologisch bestimmte - Kategorie in Karl Barths Versöhnungslehre (KD IV/2, §64.3).

${ }^{107}$ So schon Axel Honneth, der diese Aussage jedoch auf die menschliche Würde im Rechtsverhältnis bezieht, Honneth, Kampf, 203.

108 Für die hier zugrunde gelegte typologische Gegenüberstellung von Würde- und Ehrkonzept vgl. Wils, Gotteslästerung, 58-76. Natürlich zeigt auch das Konzept der Würde verschiedene, ebenfalls erfahrungsnahe Ausformungen und sind die Übergänge zum Ehrkonzept fliessend und komplexer als die hier skizzierte typologische Gegenüberstellung nahelegt.

${ }^{109}$ Appiah markiert den Bruch mit der kantischen Moralphilosophie mit dem etwas platten Satz: „Denn wenn es den Menschen schwerfällt, aus Pflicht heraus zu handeln (wie das offenkundig der Fall ist), haben wir allen Grund, dafür zu sorgen, dass sie andere Gründe haben, das Richtige $\mathrm{zu}$ tun." $\mathrm{Zu}$ diesen anderen Motivationsfaktoren zählen dann eben kritisch geläuterte Ehrformen, die nicht ,vollständig moralisiert“ sind und moralisiert werden können. „Wir brauchen lediglich einen mit der Moral vereinbaren Ehrenkodex, und das ist eine deutlich schwächere Anforderung“ (alle Zitate: Appiah, Eine Frage, 197).

${ }^{110}$ Eine bedenkenswerte, eigenständige und in anderer Weise auf der Weisheitslehre aufbauende Neuvermessung hat bereits Klaas Huizing vorgelegt: Huizing, Scham.
} 
Wir haben im 1. Kapitel unserer Ausführungen verschiedene Blockaden namhaft gemacht, die zu einer Verdrängung der Gebetsform der Klage in der systematischen Theologie geführt haben. Aus der Analyse dieser Blockaden ergab sich u.a. die Beobachtung einer defizitären phänomenalen Wahrnehmung der Klage, der auch ein Wahrnehmungsdefizit hinsichtlich möglicher Aktualitätsbezüge des Klagegebetes entsprechen muss. Im 2. und 3. Kapitel wurde darum der Versuch unternommen, exemplarisch einen Aktualitätsbezug im Blick auf den sowohl gesellschaftlich wie systematisch-theologisch bzw. ethisch relevanten Phänomenbereich „Ehre“ herauszuarbeiten. Es hat sich dabei gezeigt, dass die Klage einen ausgezeichneten spirituellen Kontext sowohl zur Benennung von Ehrverlusten und Ehrverletzungen als auch zu deren religiöser Verarbeitung bietet, sofern sie die in Frage stehenden Ehrenkodizes heilsam zu transzendieren hilft. Die Klage leistet so einen wichtigen Beitrag zur Konstitution ethischer Dispositionen im betenden Subjekt und hebt andererseits die Schwelle gewaltförmiger Reaktionen der Verletzten und Gedemütigten. Mit der Herausarbeitung dieses Beitrages der Klage zum lebenspraktischen Umgang mit Formen prekärer Ehre (durch den auch wichtige neutestamentliche Konzeptualisierungen von Ehre vorgezeichnet sind) ist deutlich geworden, wie wichtig eine umfassendere phänomenale Wahrnehmung der Klage auch für die systematische Theologie ist. Denn sie drängt dazu, die implizite und explizite „Theo-logie“ von Klagegebeten auch in systematisch-theologischer Perspektive zur Geltung zu bringen und weiterzudenken. 